Sensors and Actuators: B. Chemical

\title{
Dopamine/mucin-1 functionalized electro-active carbon nanotubes as a probe for direct competitive electrochemical immunosensing of breast cancer biomarker

\author{
--Manuscript Draft--
}

\begin{tabular}{|c|c|}
\hline Manuscript Number: & SNB-D-20-03677R3 \\
\hline Article Type: & Research Paper \\
\hline Section/Category: & Electrochemical Sensors \\
\hline Keywords: & $\begin{array}{l}\text { MWCNTs, Mucin, Gelatin, Dopamine, Electrochemical Immunosensor, Direct } \\
\text { immobilization, Competitive assay. }\end{array}$ \\
\hline Corresponding Author: & $\begin{array}{l}\text { Akhtar Hayat, Ph.D., } \\
\text { Interdisciplinary Research Centre in Biomedical Materials (IRCBM) } \\
\text { Lahore, PAKISTAN }\end{array}$ \\
\hline First Author: & Sidra Rashid, MS \\
\hline \multirow[t]{5}{*}{ Order of Authors: } & Sidra Rashid, MS \\
\hline & Mian H Nawaz, PhD \\
\hline & Ihtesham U Rehman, PhD \\
\hline & Jean L Marty, PhD \\
\hline & Akhtar Hayat, Ph.D., \\
\hline Abstract: & $\begin{array}{l}\text { Mucin-1 (MUC-1) is associated with a broad range of human epithelia including gastric, } \\
\text { lung and colorectal. In this work, a direct competitive electrochemical immunosensor } \\
\text { based on gelatin modified transduction platform was designed. Dopamine (DA)/mucin- } \\
1 \text { functionalized electro-active carbon nanotubes were employed as signal generating } \\
\text { probes in the construction of electrochemical immunosensor for early stage diagnosis } \\
\text { of breast cancer. The gelatin modified electrode served as a support to immobilize } \\
\text { antibody (anti-MUC-1), while electrochemical response of functionalized electro-active } \\
\text { carbon nano probes was used for quantitative measurement of MUC-1. Cyclic } \\
\text { Voltammetry (CV) and Electrochemical Impedance Spectroscopy (EIS) were carried } \\
\text { out to characterize the transduction surface at different fabrication steps. The } \\
\text { developed immunosensor permitted the detection of MUC-1 in the linear range of } 0.05- \\
940 \text { U } / \mathrm{mL} \text {, with a detection limit (LOD) of } 0.01 \mathrm{U} / \mathrm{mL} \text {. The immunosensor showed } \\
\text { recovery values in the range of } 96-96.67 \% \text { for human serum sample analysis, } \\
\text { demonstrating its practical applicability. }\end{array}$ \\
\hline Response to Reviewers: & $\begin{array}{l}\text { Response to the comments } \\
\text { Editor s' comments: } \\
\text { We would like to thank editor for his valuable input and feedback to improve our } \\
\text { manuscript. The entire manuscript was very carefully corrected for language and } \\
\text { grammatical errors by the English speaker and one of the coauthors, Prof Ihtesham ur } \\
\text { Rehman (Bioengineering, Engineering Department, Lancaster University, Lancaster, } \\
\text { UK). He is also serving as editor for following journals; Editor for Europe: Applied } \\
\text { Spectroscopy Reviews; International Journal of Molecular Sciences; "Recent Advances } \\
\text { in Dental Materials and Biomaterials". } \\
\text { Grammatical Mistakes } \\
\text { No. CommentsResponsePage no.Line no. } \\
\text { 1(line 83) The authors defined the abbreviation as "Gelatin (GL)". In other parts of the } \\
\text { text, the abbreviation is not used. The abbreviation is not necessary. The Abbreviation } \\
\text { is deleted from the entire manuscript. } \\
\text { 2(line 90) What is the "antigen a"?The typo error was corrected; } \\
\text { "antigen a" was replaced by "antigen"0391 } \\
\text { 3ls the company name "HB Tokyo Japan" correct? "HB" may be the hardness of the } \\
\text { lead of the pencil.The correction was made; } \\
\text { The pencil graphite electrodes (PGE, } 0.5 \text { mm lead diameter) were purchased from } \\
\text { Staedtler Mars GmbH \&amp; Co. KG, Germany.05132-133 } \\
4 \text { It says "in tail-on called tail down orientation.[24]". What do you mean?The } \\
\text { information was included in the revised manuscript }\end{array}$ \\
\hline
\end{tabular}


"tail-on orientation (Fc attached to the surface)"07206

5The abbreviation "EIS" is defined three times in the text. It is enough to define abbreviations only once. The authors should check all the abbreviations. The correction was made;

The EIS abbreviation is defined once in the entire manuscript. Moreover, all the abbreviations are carefully checked for the same

0122

6(line 337) Although the authors use "Et" as the abbreviation of electrochemical, many "electrochemical" are used without abbreviation in the text. I do not think the abbreviations is necessary. The Abbreviation is deleted from the entire manuscript. 7It says "The impedimetric response was analogue of the CV response (Fig. 5B).". What do you mean?The correction was made;

"The trend of the impedimetric response of all the fabrication steps was found to be the analogue of their CV response as can be evidenced in the Fig. 5A and 5B."14365-367 8It says "The calibration curve (Fig. 7B) was fitted by sigmoidal logistic four parameterequation $y=y 0+(a / 1+(x / x 0) b)$ ". This is really strange. The equation represents $a$ linear relation. The correction was made in the equation;

"The calibration curve (Fig. 7B) was fitted by sigmoidal logistic four parameter-equation $y=a 2+[a 1-a 2 / 1+(x / x 0) p]$ using Origin Pro-8 SR0 software, in which a2 and a1 are the maximum and minimum values respectively, and $x 0$ and $p$ are the $x$ value at the inflection point and the slope of inflection point accordingly."16428-431

9In line 34, it says "of biomarkers. [1].". There are two periods at the end of the sentence. Many minor errors of this kind are found in lines 46, 49, 83, 103, 106, 129, 231, 286, 287, 294, 296, 347, 348, 403, 409, 410, 474, 478, 505. The authors should correct all of them by themselves.

The entire manuscript was carefully revised for such minor errors

10(line 49) However, the presence of strong van der Waals interactions among MWCNTs hold them tightly togetherThe correction was made;

"However, the presence of strong Van der Waals interactions among MWCNTs results their aggregation which limits their applications"0252-54

11(line 121) XRD analysis were performed withThe correction was made;

"XRD spectra were obtained from..."04123

12(line 160) while EDC/NHS chemistry was carried for GL activation on the electrode surface. The correction was made;

"The crosslinkers (EDC and NHS) were used to activate the carboxylic groups of gelatin on the electrode surface."06162-163

13 (line 194) as on the specific surface. The correction was made;

"on the substrate surface."07196

14(line 195) The carboxylic acid function of these amino acids, The correction was made;

"The carboxylic acid functional groups"07197

15(line 198) as amino acids are present in excess, therefore ... The correction was made;

"In general, the presence of excessive amount of amino acids can theoretically result in a random immobilization."07199-200

16(line 231) This immunosensor was first scanned in ferri/ferro cyanide solution and then in PBS solution using $\mathrm{CV}$ as the initial signal. The correction was made;

"The immunosensor was characterized both in ferri/ferro cyanide solution and PBS buffer."08229

17(line 254) the band appeared from $2200 \mathrm{~cm}-1$ to $2300 \mathrm{~cm}-1$ was assigned to CO2. The correction was made;

"Similarly, the spectral band at 2200 to $2300 \mathrm{~cm}-1$ was assigned to CO2."09251-252 18 (line 287) with very well separation characteristics. .The correction was made; "After interaction of DA (Fig. 2D), the modified MWCNTs were found to be disaggregated."10282-283

19(line 294) in comparison to that of obtained for MWCNTsThe correction was made: "The intensity of 002 peak for fMWCNTs was increased as compared to pristine MWCNTs"11289-290

20(line 376) in (1 mM) of [Fe (CN)6]4-/3-solutionThe correction was made; of $1 \mathrm{mM}$ redox couple [Fe (CN)6]4-/3- .14371

21 (line 400) As for the expression of "Figure" in the text, the authors should follow the rule of this journal.The Figure expression was corrected in the entire manuscript as per the journal format.

22(line 423) Both labelled and un labelled antigen have ... The correction was made; 
"Both labelled and un-labelled antigens have..."16418

23(line 427) The decrease response was ... The correction was made;

"The decrease in response was.." 16422

24(line 429) the change in current signal was difficult to observed ...The correction was made;

"the change in current response was difficult to be observed"16424-425

250ther than these, there are nouns without appropriate articles. The entire manuscript was carefully revised for such nouns errors 
Tel: +923317648259

E-mail: akhtarhayat@cuilahore.edu.pk

December 122020

\section{Dear Editor}

We should like to submit our revised manuscript entitled: "Dopamine/mucin-1 functionalized electro-active carbon nanotubes as a probe for direct competitive electrochemical immunosensing of breast cancer biomarker"

We would like to thank editor for his valuable input and feedback to improve our manuscript. The entire manuscript was very carefully corrected for language and grammatical errors by the English speaker and one of the coauthors, Prof Ihtesham ur Rehman (Bioengineering, Engineering Department, Lancaster University, Lancaster, UK). He is also serving as editor for following journals; Editor for Europe: Applied Spectroscopy Reviews; International Journal of Molecular Sciences; "Recent Advances in Dental Materials and Biomaterials".

The changes are highlighted in red in the revised manuscript for your consideration. We hope that the current version of the manuscript fulfills the quality criteria for publication in this esteemed journal.

With best regards

Dr Akhtar Hayat $(\mathrm{PhD})$

Associate professor

IRCBM, CUI Lahore

Pakistan 
Editor s' comments:

\section{Response to the comments}

We would like to thank editor for his valuable input and feedback to improve our manuscript. The entire manuscript was very carefully corrected for language and grammatical errors by the English speaker and one of the coauthors, Prof Ihtesham ur Rehman (Bioengineering, Engineering Department, Lancaster University, Lancaster, UK). He is also serving as editor for following journals; Editor for Europe: Applied Spectroscopy Reviews; International Journal of Molecular Sciences; "Recent Advances in Dental Materials and Biomaterials".

\begin{tabular}{|c|c|c|c|c|}
\hline \multicolumn{5}{|c|}{ Grammatical Mistakes } \\
\hline No & Comments & Response & $\begin{array}{l}\text { Page } \\
\text { no. }\end{array}$ & $\begin{array}{l}\text { Line } \\
\text { no. }\end{array}$ \\
\hline 1 & $\begin{array}{l}\text { (line } 83 \text { ) The authors } \\
\text { defined the abbreviation } \\
\text { as "Gelatin (GL)". In } \\
\text { other parts of the text, } \\
\text { the abbreviation is not } \\
\text { used. The abbreviation is } \\
\text { not necessary. }\end{array}$ & $\begin{array}{l}\text { The Abbreviation is deleted from the } \\
\text { entire manuscript. }\end{array}$ & & \\
\hline 2 & $\begin{array}{l}\text { (line 90) What is the } \\
\text { "antigen a"? }\end{array}$ & $\begin{array}{l}\text { The typo error was corrected; } \\
\text { "antigen a" was replaced by "antigen" }\end{array}$ & 03 & 91 \\
\hline 3 & $\begin{array}{l}\text { Is the company name } \\
\text { "HB Tokyo Japan" } \\
\text { correct? "HB" may be } \\
\text { the hardness of the lead } \\
\text { of the pencil. }\end{array}$ & $\begin{array}{l}\text { The correction was made; } \\
\text { The pencil graphite electrodes (PGE, } \\
0.5 \mathrm{~mm} \text { lead diameter) were purchased } \\
\text { from Staedtler Mars GmbH \&amp; Co. } \\
\text { KG, Germany. }\end{array}$ & 05 & $\begin{array}{l}132- \\
133\end{array}$ \\
\hline 4 & $\begin{array}{l}\text { It says "in tail-on called } \\
\text { tail down } \\
\text { orientation.[24]". What } \\
\text { do you mean? }\end{array}$ & $\begin{array}{l}\text { The information was included in the } \\
\text { revised manuscript } \\
\text { "tail-on orientation (Fc attached to the } \\
\text { surface)" }\end{array}$ & 07 & 206 \\
\hline 5 & $\begin{array}{l}\text { The abbreviation "EIS" } \\
\text { is defined three times in } \\
\text { the text. It is enough to } \\
\text { define abbreviations only } \\
\text { once. The authors should } \\
\text { check all the } \\
\text { abbreviations. }\end{array}$ & $\begin{array}{l}\text { The correction was made; } \\
\text { The EIS abbreviation is defined once in } \\
\text { the entire manuscript. Moreover, all the } \\
\text { abbreviations are carefully checked for } \\
\text { the same }\end{array}$ & 01 & 22 \\
\hline 6 & $\begin{array}{l}\text { (line } 337 \text { ) Although the } \\
\text { authors use "Et" as the } \\
\text { abbreviation of } \\
\text { electrochemical, many } \\
\text { "electrochemical" are } \\
\text { used without } \\
\text { abbreviation in the text. I } \\
\text { do not think the } \\
\text { abbreviations is } \\
\text { necessary. }\end{array}$ & $\begin{array}{l}\text { The Abbreviation is deleted from the } \\
\text { entire manuscript. }\end{array}$ & & \\
\hline 7 & $\begin{array}{l}\text { It says "The } \\
\text { impedimetric response } \\
\text { was analogue of the } \mathrm{CV}\end{array}$ & $\begin{array}{l}\text { The correction was made; } \\
\text { "The trend of the impedimetric response } \\
\text { of all the fabrication steps was found to }\end{array}$ & 14 & $\begin{array}{l}365- \\
367\end{array}$ \\
\hline
\end{tabular}




\begin{tabular}{|c|c|c|c|c|}
\hline & $\begin{array}{l}\text { response (Fig. 5B).”. } \\
\text { What do you mean? }\end{array}$ & $\begin{array}{l}\text { be the analogue of their } \mathrm{CV} \text { response as } \\
\text { can be evidenced in the Fig. } 5 \mathrm{~A} \text { and } \\
5 \mathrm{~B} . "\end{array}$ & & \\
\hline 8 & $\begin{array}{l}\text { It says "The calibration } \\
\text { curve (Fig. 7B) was } \\
\text { fitted by sigmoidal } \\
\text { logistic four parameter- } \\
\text { equation y }=y 0+(\mathrm{a} / 1+ \\
(\mathrm{x} / \mathrm{x} 0) \mathrm{b}) \text { ". This is really } \\
\text { strange. The equation } \\
\text { represents a linear } \\
\text { relation. }\end{array}$ & $\begin{array}{l}\text { The correction was made in the } \\
\text { equation; } \\
\text { "The calibration curve (Fig. 7B) was } \\
\text { fitted by sigmoidal logistic four } \\
\text { parameter-equation } \mathrm{y}=\mathrm{a}_{2}+\left[\mathrm{a}_{1}-\mathrm{a}_{2} / 1+\right. \\
\left.\left(\mathrm{x} / \mathrm{x}_{0}\right)^{p}\right] \text { using Origin Pro- } 8 \text { SR0 } \\
\text { software, in which } \mathrm{a}_{2} \text { and } \mathrm{a}_{1} \text { are the } \\
\text { maximum and minimum values } \\
\text { respectively, and } \mathrm{x}_{0} \text { and } p \text { are the } \mathrm{x} \\
\text { value at the inflection point and the } \\
\text { slope of inflection point accordingly." }\end{array}$ & 16 & $\begin{array}{l}428- \\
431\end{array}$ \\
\hline 9 & $\begin{array}{l}\text { In line } 34, \text { it says "of } \\
\text { biomarkers. [1].". There } \\
\text { are two periods at the } \\
\text { end of the sentence. } \\
\text { Many minor errors of } \\
\text { this kind are found in } \\
\text { lines } 46,49,83,103 \text {, } \\
106,129,231,286,287 \text {, } \\
294,296,347,348,403 \text {, } \\
409,410,474,478,505 \text {. } \\
\text { The authors should } \\
\text { correct all of them by } \\
\text { themselves. }\end{array}$ & $\begin{array}{l}\text { The entire manuscript was carefully } \\
\text { revised for such minor errors }\end{array}$ & & \\
\hline 10 & $\begin{array}{l}\text { (line 49) However, the } \\
\text { presence of strong van } \\
\text { der Waals interactions } \\
\text { among MWCNTs hold } \\
\text { them tightly together }\end{array}$ & $\begin{array}{l}\text { The correction was made; } \\
\text { "However, the presence of strong Van } \\
\text { der Waals interactions among } \\
\text { MWCNTs results their aggregation } \\
\text { which limits their applications" }\end{array}$ & 02 & $52-54$ \\
\hline 11 & $\begin{array}{l}\text { (line 121) XRD analysis } \\
\text { were performed with }\end{array}$ & $\begin{array}{l}\text { The correction was made; } \\
\text { "XRD spectra were obtained from..." }\end{array}$ & 04 & 123 \\
\hline 12 & $\begin{array}{l}\text { (line } 160) \text { while } \\
\text { EDC/NHS chemistry } \\
\text { was carried for GL } \\
\text { activation on the } \\
\text { electrode surface. }\end{array}$ & $\begin{array}{l}\text { The correction was made; } \\
\text { "The crosslinkers (EDC and NHS) were } \\
\text { used to activate the carboxylic groups of } \\
\text { gelatin on the electrode surface." }\end{array}$ & 06 & $\begin{array}{l}162- \\
163\end{array}$ \\
\hline 13 & $\begin{array}{l}\text { (line 194) as on the } \\
\text { specific surface. }\end{array}$ & $\begin{array}{l}\text { The correction was made; } \\
\text { "on the substrate surface." }\end{array}$ & 07 & 196 \\
\hline 14 & $\begin{array}{l}\text { (line 195) The carboxylic } \\
\text { acid function of these } \\
\text { amino acids, }\end{array}$ & $\begin{array}{l}\text { The correction was made; } \\
\text { "The carboxylic acid functional groups" }\end{array}$ & 07 & 197 \\
\hline 15 & $\begin{array}{l}\text { (line 198) as amino acids } \\
\text { are present in excess, } \\
\text { therefore ... }\end{array}$ & $\begin{array}{l}\text { The correction was made; } \\
\text { "In general, the presence of excessive } \\
\text { amount of amino acids can theoretically } \\
\text { result in a random immobilization." }\end{array}$ & 07 & $\begin{array}{l}199- \\
200\end{array}$ \\
\hline 16 & (line 231) & The correction was made; & 08 & 229 \\
\hline
\end{tabular}




\begin{tabular}{|c|c|c|c|c|}
\hline & $\begin{array}{l}\text { immunosensor was first } \\
\text { scanned in ferri/ferro } \\
\text { cyanide solution and then } \\
\text { in PBS solution using } \\
\text { CV as the initial signal. }\end{array}$ & $\begin{array}{l}\text { "The immunosensor was characterized } \\
\text { both in ferri/ferro cyanide solution and } \\
\text { PBS buffer." }\end{array}$ & & \\
\hline 17 & $\begin{array}{l}\text { (line 254) the band } \\
\text { appeared from } 2200 \mathrm{~cm}- \\
1 \text { to } 2300 \mathrm{~cm}-1 \text { was } \\
\text { assigned to } \mathrm{CO} 2 .\end{array}$ & $\begin{array}{l}\text { The correction was made; } \\
\text { "Similarly, the spectral band at } 2200 \text { to } \\
2300 \mathrm{~cm}-1 \text { was assigned to CO2." }\end{array}$ & 09 & $\begin{array}{l}251- \\
252\end{array}$ \\
\hline 18 & $\begin{array}{l}\text { (line } 287) \text { with very well } \\
\text { separation } \\
\text { characteristics. . }\end{array}$ & $\begin{array}{l}\text { The correction was made; } \\
\text { "After interaction of DA (Fig. 2D), the } \\
\text { modified MWCNTs were found to be } \\
\text { disaggregated." }\end{array}$ & 10 & $\begin{array}{l}282- \\
283\end{array}$ \\
\hline 19 & $\begin{array}{l}\text { (line 294) in comparison } \\
\text { to that of obtained for } \\
\text { MWCNTs }\end{array}$ & $\begin{array}{l}\text { The correction was made; } \\
\text { "The intensity of } 002 \text { peak for } \\
\text { fMWCNTs was increased as compared } \\
\text { to pristine MWCNTs" }\end{array}$ & 11 & $\begin{array}{l}289- \\
290\end{array}$ \\
\hline 20 & $\begin{array}{l}\text { (line 376) in }(1 \mathrm{mM}) \text { of } \\
{[\mathrm{Fe}(\mathrm{CN}) 6] 4-/ 3 \text {-solution }}\end{array}$ & $\begin{array}{l}\text { The correction was made; } \\
\text { of } 1 \mathrm{mM} \text { redox couple }\left[\mathrm{Fe}(\mathrm{CN})_{6}\right]^{4-/ 3-}\end{array}$ & 14 & 371 \\
\hline 21 & $\begin{array}{l}\text { (line 400) As for the } \\
\text { expression of "Figure" in } \\
\text { the text, the authors } \\
\text { should follow the rule of } \\
\text { this journal. }\end{array}$ & $\begin{array}{l}\text { The Figure expression was corrected in } \\
\text { the entire manuscript as per the journal } \\
\text { format. }\end{array}$ & & \\
\hline 22 & $\begin{array}{l}\text { (line } 423 \text { ) Both labelled } \\
\text { and un labelled antigen } \\
\text { have ... }\end{array}$ & $\begin{array}{l}\text { The correction was made; } \\
\text { "Both labelled and un-labelled antigens } \\
\text { have..." }\end{array}$ & 16 & 418 \\
\hline 23 & $\begin{array}{l}\text { (line } 427) \text { The decrease } \\
\text { response was ... }\end{array}$ & $\begin{array}{l}\text { The correction was made; } \\
\text { "The decrease in response was.." }\end{array}$ & 16 & 422 \\
\hline 24 & $\begin{array}{l}\text { (line 429) the change in } \\
\text { current signal was } \\
\text { difficult to observed ... }\end{array}$ & $\begin{array}{l}\text { The correction was made; } \\
\text { "the change in current response was } \\
\text { difficult to be observed" }\end{array}$ & 16 & $\begin{array}{l}424- \\
425\end{array}$ \\
\hline 25 & $\begin{array}{l}\text { Other than these, there } \\
\text { are nouns without } \\
\text { appropriate articles. }\end{array}$ & $\begin{array}{l}\text { The entire manuscript was carefully } \\
\text { revised for such nouns errors }\end{array}$ & & \\
\hline
\end{tabular}




\section{Highlights}

1. Detection of MUC-1 is critical but difficult due to its trace amount in the serum of early cancer patients.

2. Dopamine can provide an amplified signal because of its electron donating capability.

3. Gelatin consists of large number of carboxylic/ amine groups that can provide a specific immobilization support to antibodies or antigens.

4. DA/MUC-1/fMWCNT nanoprobe provided an amplified current signal which was high enough to carry out the competition step with improved sensitivity. 


\title{
Dopamine/mucin-1 functionalized electro-active carbon nanotubes as a probe for direct competitive electrochemical immunosensing of breast cancer biomarker
}

\author{
Sidra Rashid ${ }^{1}$, Mian Hasnain Nawaz ${ }^{1}$, Ihtesham ur Rehman ${ }^{2}$, Akhtar Hayat ${ }^{1}$, Jean \\ Loius Marty ${ }^{3 *}$. \\ 1. Interdisciplinary Research Centre in Biomedical Materials (IRCBM), COMSATS \\ University Islamabad, Lahore Campus, Pakistan. \\ 2. Bioengineering, Engineering Department, Lancaster University, Lancaster, UK \\ 3. Sensbiotech, 21rue de Nogarede, 66400 Ceret, France. \\ *Corresponding author: akhtarhayat@cuilahore.edu.pk; sensbiotech@gmail.com
}

\section{Abstract}

Mucin-1 (MUC-1) is associated with a broad range of human epithelia including gastric, lung and colorectal. In this work, a direct competitive electrochemical immunosensor based on gelatin modified transduction platform was designed. Dopamine (DA)/mucin-1 functionalized electro-active carbon nanotubes were employed as signal generating probes in the construction of electrochemical immunosensor for early stage diagnosis of breast cancer. The gelatin modified electrode served as a support to immobilize antibody (anti-MUC-1), while electrochemical response of functionalized electro-active carbon nano probes was used for quantitative measurement of MUC-1. Cyclic Voltammetry (CV) and Electrochemical Impedance Spectroscopy (EIS) were carried out to characterize the transduction surface at different fabrication steps. The developed immunosensor permitted the detection of MUC-1 in the linear range of $0.05-940 \mathrm{U} / \mathrm{mL}$, with a detection limit (LOD) of $0.01 \mathrm{U} / \mathrm{mL}$. The immunosensor showed recovery values in the range of $96-96.67 \%$ for human serum sample analysis, demonstrating its practical applicability.

Key words: MWCNTs, Mucin, Gelatin, Dopamine, Electrochemical Immunosensor, Direct immobilization, Competitive assay. 


\section{Introduction}

Breast cancer is one of the most common causes of women mortality. The mortality rate can be reduced to a significant level with the early stage diagnosis of breast cancer biomarkers [1]. However, the trace level of biomarkers in the serum of early cancer patients is one of the limiting factors towards diagnosis [2]. In this context, increasing demand for the detection of ultralow amount of cancer biomarkers has resulted in the exploration of different signal amplification strategies towards fabrication of ultrasensitive electrochemical immunoassays [3]. Several traditional techniques including radioimmunoassay, enzyme-linked immunosorbent assay (ELISA), electrophoretic immunoassay, fluorescence immunoassay, immune-polymerase chain reaction (PCR) and mass spectrometric immunoassay have been used for this purpose. However, they undergo operational limitations and hence, it is highly desirable to develop ultrasensitive, simple and easily automated device for early diagnosis of cancer biomarkers [4]. Electrochemical immunosensors with inherent advantages of cost effectiveness, higher sensitivity and lower power requirement have been applied for clinical diagnosis [5].

In such ultrasensitive immunosensors, nanomaterials can either be used directly as an electroactive label or as a substrate material to immobilize the electro-active labels [6]. Among the wide range of nanomaterials, multi-walled carbon nanotubes (MWCNTs) have been considered as a very promising material to enhance electron transfer rate on the transducer surface. Owing to their intrinsic electrical and electrochemical properties, MWCNTs are highly suitable for their integration into sensing strategies [7]. However, the presence of strong Van der Waals interactions among MWCNTs results their aggregation which limits their applications [8]. In this direction, the introduction of highly active functional groups via covalent modification of MWCNTs could enhance the electrochemical features of MWCNTs. For instance, the introduction of carboxylic groups on MWCNTs could covalently bond the amine residues of biological receptor elements [9]. Such biomolecule coated nanomaterials have been applied for the recognition of analytes. Consequently, electrostatically and covalently coupled carbon nanotubes not only stabilize the biomolecules but also offer distinct advantages including higher binding capacity, improved stability and reduced cost per assay [10, 11]. Currently, MWCNTs coated with both, biological recognition elements and electro-active labels have been investigated simultaneously, for molecular recognition and signal amplification [12]. 
DA is an important member of the catechol family, which is hydrophilic in nature and considered as an electron donor with variable redox properties [13]. DA and its derivatives have been reported to design signal amplification probes for construction of electrochemical biosensors [14]. Furthermore, the functional groups of DA including amine, imine, quinone and catechol enable DA to bind with a broad range of biomolecules [15]. In this regard, we have developed a DA coated MUC-1 conjugated MWCNTs nanoprobe. The MUC-1 was linked through amide bond formation with MWCNTs, while with DA using its amine and carboxylic groups respectively. This nanoprobe was subsequently integrated with carbon interface of working electrode to construct a direct competitive electrochemical immunosensor.

On the other hand, despite the advantages of nano-amplification technologies in electrochemical immunosensor, the unmodified electrodes are prone to major drawbacks of poor sensitivity, higher oxidation potential and fouling of the electrode response [16]. To overcome these problems, modification of the electrode surface with appropriate materials is of critical importance. Besides providing specific immobilization support for recognition elements, natural polymers have the ability to overcome the disadvantages of biological damages and toxicity imposed by non-biological transducing materials [17]. In this direction, it is highly desirable to fabricate a transducer surface with increased number of binding sites to improve the analytical merits of the biosensor. Amino acids modified transducer platforms provide a high surface area and abundant functional groups, which subsequently improve their stability and sensitivity. Gelatin is a linear polypeptide with large number of amine/carboxylic functional groups which provide a specific immobilization support for bioreceptors to design electrochemical biosensors [18]. The electro-oxidation of gelatin can render free amine groups on the transducer surface for interaction with carboxylic groups of Fc region of antibody [19]. Thus, it provides an efficient platform for the effective immobilization of the antibody [20]. Antibody immobilization on the electrode is considered to determine the surface charge of the transducer surface. This surface charge undergoes alteration upon immunoreaction with the given antigen [21]. Moreover, direct immobilization of biorecognition elements via covalent modification is known to improve the sensitivity of electrochemical immunosensors for various applications [22]. Direct assays involving antibody immobilization on modified electrode offer the advantages of sensitivity and stability over the indirect strategies. In addition, the immobilization of antibody on modified electrode can recognise even the low level of analyte for diagnostic purpose [23]. 
Keeping in view the above objectives, a direct electrochemical immunosensor based on DA coated MUC-1 conjugated functionalized multi walled carbon nanotubes (DA/MUC1/fMWCNTs) was fabricated for the competitive detection of MUC-1. MWCNTs were used to provide large surface area, while DA was employed to attain better sensitivity towards the target analyte. This fabrication approach resulted in a highly sensitive and selective transduction platform for the analysis of MUC-1 biomarker. The designed strategy was demonstrated for the analysis of breast cancer biomarker, however, it can be very easily extended to other biomarkers for diverse applications.

\section{Experimental Details}

\subsection{Materials}

Potassium ferrocyanide $\left(\mathrm{K}_{4}\left[\mathrm{Fe}(\mathrm{CN})_{6}\right]\right)$, Sulfuric acid $\left(\mathrm{H}_{2} \mathrm{SO}_{4}, 98 \%\right)$, potassium ferricyanide $\left(\mathrm{K}_{3}\left[\mathrm{Fe}(\mathrm{CN})_{6}\right]\right)$, bovine serum albumin (BSA), fetal bovine serum (FBS), human serum and Prestige Antibodies (NS1) were purchased from Sigma (Taufkirchen, Germany). Cancer antigen mucin $(25 \mathrm{kU})$ was purchased from Lee bio (Maryland Heights, MO, USA). Lysozyme was purchased from Carbosynth (Berkshire, UK), while N-(3dimethylaminopropyle)-N-ethyle-carbodiimide hydrochloride (EDC) and N-hydroxy succinimide (NHS) were from Alfa Aesar (Heysham, UK). MWCNTs (D $\times$ L 4-5 nm × 0.5$1.5 \mu \mathrm{m})$ were purchased from Sigma-Aldrich, France.

\subsection{Apparatus}

Different spectroscopic techniques were employed to characterize the nanoprobe and immunosensor fabrication steps. Fourier transform infrared (FTIR) measurements were performed by using a Thermo Nicolet $6700^{\mathrm{TM}}$ spectrometer (Waltham, MA, USA). Scanning electron microscopy (SEM) studies were performed by using a VEGA-3-TESCAN (Brno, Czech Republic) with variable pressure mode (LMU). Images were taken in different magnification ranges at an accelerated voltage of $20 \mathrm{kV}$. UV-Visible (UV-Vis) measurements were performed with a UV-spectrophotometer (UV-1800, USA) that was equipped with UV probe software to measure the absorption parameters. XRD spectra were obtained from a Rigaku D/Max 2500 XRD (Rigaku Corp Japan), equipped with graphitic mono-chromator $(40 \mathrm{kV}, 40 \mathrm{~mA})$. A nickel filtered $\mathrm{Cu}-\mathrm{K} \alpha$ radiation source $(\lambda=1.5418 \AA)$ was used during the sample analysis. To inspect the surface topography, atomic force microscopy (AFM) was performed at AFM PARK XE-7 Systems (Suwon Korea) in noncontact mode. 
For electrochemical measurements, AMEL 2553, potentiostat/galvanostat equipped with ZPulse software was used. A conventional three electrode system with $\mathrm{Ag} / \mathrm{AgCl}$ as reference electrode, a pencil graphite electrode as working electrode and platinum wire as counter electrode was employed. The pencil graphite electrodes (PGE, $0.5 \mathrm{~mm}$ lead diameter) were purchased from Staedtler Mars GmbH \&amp; Co. KG, Germany. An electrode length measuring $1 \mathrm{~cm}$ was immersed in a solution per measurement to maintain the uniform surface area for all the electrochemical experiments. EIS experiments were carried out using $\left[\mathrm{Fe}(\mathrm{CN})_{6}\right]^{4-/ 3-}$ as a redox probe under an applied potential of $0.1 \mathrm{~V}$ (vs. $\mathrm{Ag} / \mathrm{AgCl}$ reference electrode). The frequency range was between $100 \mathrm{kHz}-0.2 \mathrm{~Hz}$, with an AC amplitude and sampling rate of $10 \mathrm{mV}$ and 10 points respectively. The EIS spectra were plotted in the form of complex plane diagrams (Nyquist plots, -Zim vs. Zre) and fitted to a theoretical curve corresponding to the equivalent circuit with a frequency response analyzer software (FRA).

\subsection{Preparation of nanoprobe}

To obtain the carboxy functionalized MWCNTs, a homogenous solution of MWCNTs was prepared $(2 \mathrm{mg} / \mathrm{mL})$ in distilled $\mathrm{H}_{2} \mathrm{O}$ under ultrasonication for 2 hours. Subsequently, chloroacetic acid $(1 \mathrm{~g} / \mathrm{mL})$ and $\mathrm{NaOH}(1.5 \mathrm{~g} / \mathrm{mL})$ were added to the reaction suspension. After sonication, supernatant was removed and remaining solution was allowed to dry. Then, fMWCNTs were treated with $100 \mathrm{mM}$ EDC-NHS solution containing MUC-1 protein for 45 min. For MUC-1 conjugation, $200 \mu \mathrm{L}$ of MUC-1 protein (1/100 dilution from stock solution) was mixed with the solution of NHS $(25 \mathrm{mM})$ and EDC $(100 \mathrm{mM})$ in the Phosphate Buffer Saline (PBS, $\mathrm{pH}$ - 7.4) for $45 \mathrm{~min}$. Subsequently, the supernatant was removed via centrifuge at $12000 \mathrm{rpm}$ to obtain the MUC-1 conjugated fMWCNTs. MWCNTs provided a large surface area for the attachment of MUC-1 protein to make a stable and promising immunosensing platform. Afterwards, DA $(1 \mathrm{mg} / \mathrm{mL})$ was added in the reaction mixture under vigorous stirring for $20 \mathrm{~min}$. The mixture was allowed to settle down. Excessive water was removed and left over was directly used for immunosensor fabrication.

\subsection{Fabrication of competitive electrochemical immunosensor}

Prior to gelatin grafting, the PGE was electrochemically cleaned in $0.5 \mathrm{M} \mathrm{H}_{2} \mathrm{SO}_{4}$ to reduce/oxidize impurities by successive cyclic voltammetric scans within the potential range from -1.5 to $1.5 \mathrm{~V}$. For electro oxidation of gelatin, the solution of gelatin $(2.5 \mathrm{mg} / \mathrm{mL})$ was prepared in acetate buffer $(\mathrm{pH}=5)$ at room temperature. Two consecutive cyclic voltammetric scans were run at a scan rate of $0.5 \mathrm{~V} / \mathrm{s}$ in the potential range from -1.2 to $0.4 \mathrm{~V}$ for the electro oxidation of gelatin on PGE surface. The modified electrode 
was incubated in $25 \mu \mathrm{L}$ of MUC-1 antibody solution $(0.25 \mathrm{U} / \mathrm{mL})$. The crosslinkers (EDC and NHS) were used to activate the carboxylic groups of gelatin on the electrode surface. The Electrode was then washed with PBS solution to remove the excess of unbound antibody. To block the residual carboxylic sites, diethanolamine was incubated on the electrode surface for a time period of $45 \mathrm{~min}$. For MUC-1 detection, $25 \mu \mathrm{L}$ of nanoprobe was incubated on the modified electrode surface for $45 \mathrm{~min}$. For the selectivity experiments of the fabricated immunosensor, various interfering moieties including FBS, BSA and NS1 were incubated on the sensor surface following a procedure similar to the one described for MUC-1 analysis.

\subsection{Quantitative detection of MUC-1}

Based on the principle of competitive-assay, the fabricated immunosensor was incubated with different concentrations of free MUC-1 for $15 \mathrm{~min}$ and subsequently washed with the PBS buffer. The peak current was recorded using the electrochemical workstation. The difference in the corresponding peak before and after the competition step was used for the quantitative analysis of MUC-1.

\subsection{Real Sample Analysis}

To validate the potential application of proposed immunosensor in clinical analysis, MUC-1 spiked human serum samples were analysed. Human serum was diluted (50 times) with PBS buffer to achieve the desired analyte concentration. The samples were spiked with three different concentrations of the analyte $(0.1,14.8$ and $473.6 \mathrm{U} / \mathrm{mL})$.

\section{Results and discussion}

\subsection{Detection mechanism of electrochemical immunosensor}

The mechanism of proposed electrochemical immunosensor based on DA assisted signal amplification strategy was presented in scheme 1 .

The detection strategy consists of three main steps: preparation of nanoprobe, modification of electrode surface and competitive recognition of free MUC-1. fMWCNTs provided - $\mathrm{COOH}$ groups for the attachment of MUC 1 protein, while DA was used to amplify the electrochemical signal due to its electron donating capability. The DA/MUC-1/fMWCNTs nanoprobe was synthesised by covalent binding of MUC-1 protein with DA. A robust way to create bio-functionalized surface is to immobilize the biological macromolecules such as antibodies or antigens at the modified electrode surface by means of covalent binding. This requires the presence of two mutually reactive chemical groups on the protein and on the 
substrate surface. The commonly employed literature methods exploit the reactivity of endogenous functional groups (such as amines and carboxylic acid groups) present in the side chains of the amino acids. In such strategies, the naturally occurring functional groups are used to covalently couple with the complementary functional groups present on the substrate surface. The carboxylic acid functional groups of these amino acids can react with amines using the coupling chemistry. This coupling reaction is usually activated by EDC/NHS agents which results in a rapid formation of a peptide bond. In general, the presence of excessive amount of amino acids can theoretically result in a random immobilization. However, immobilization methods based on covalent binding chemistry can provide surface coatings with a unique orientation of the antibody (Abs)-proteins. This covalent immobilization, in principle, provides the best entry point for Abs molecules to the protein (gelatin) modified surface with a specific orientation. This intermediated protein (gelatin) on electrode surface actually displays two and five binding domains specific to the Fc-portion of Abs that renders tail-on orientation (Fc attached to the surface) [24]. Um et al. introduced tail-on orientation of the Abs by the electrochemical immobilizing of a protein onto the electrode surface [25]. The electrostatic interactions between various functional groups such as amino groups on the modified (with gelatin in this case) surface and the oxygen containing groups of the $\mathrm{Ab}$ present in the $\mathrm{Fc}$ region also favour tail-on orientations of Abs due to steric hindrance imposed by side arms of the Abs. Abs possess only one binding site. Therefore, Abs should display free antigen-binding regions after immobilization to achieve the highest analyte binding. Thus, this tail-on orientation can improve biosensor performance with improvement factors as high as 200 being reported upon organized orientation [26]. Moreover, EDC/NHS activation approach possesses many merits including high conversion efficiency, mild reaction conditions, highly oriented biocompatibility with target molecules, and much cleaner products as compared to other crosslinking reagents. Therefore, the modified electrode in the strategy employed in this study with improved electro-active area supplied a non-random immobilized surface for MUC-1 antibody. The antibody was well oriented in this arrangement because of EDC assisted $-\mathrm{HN}-\mathrm{COOH}$ bond formation with gelatin-surface. In addition, the maximum numbers of MUC-1 antibody active sites were prone to epitopes attachment. 


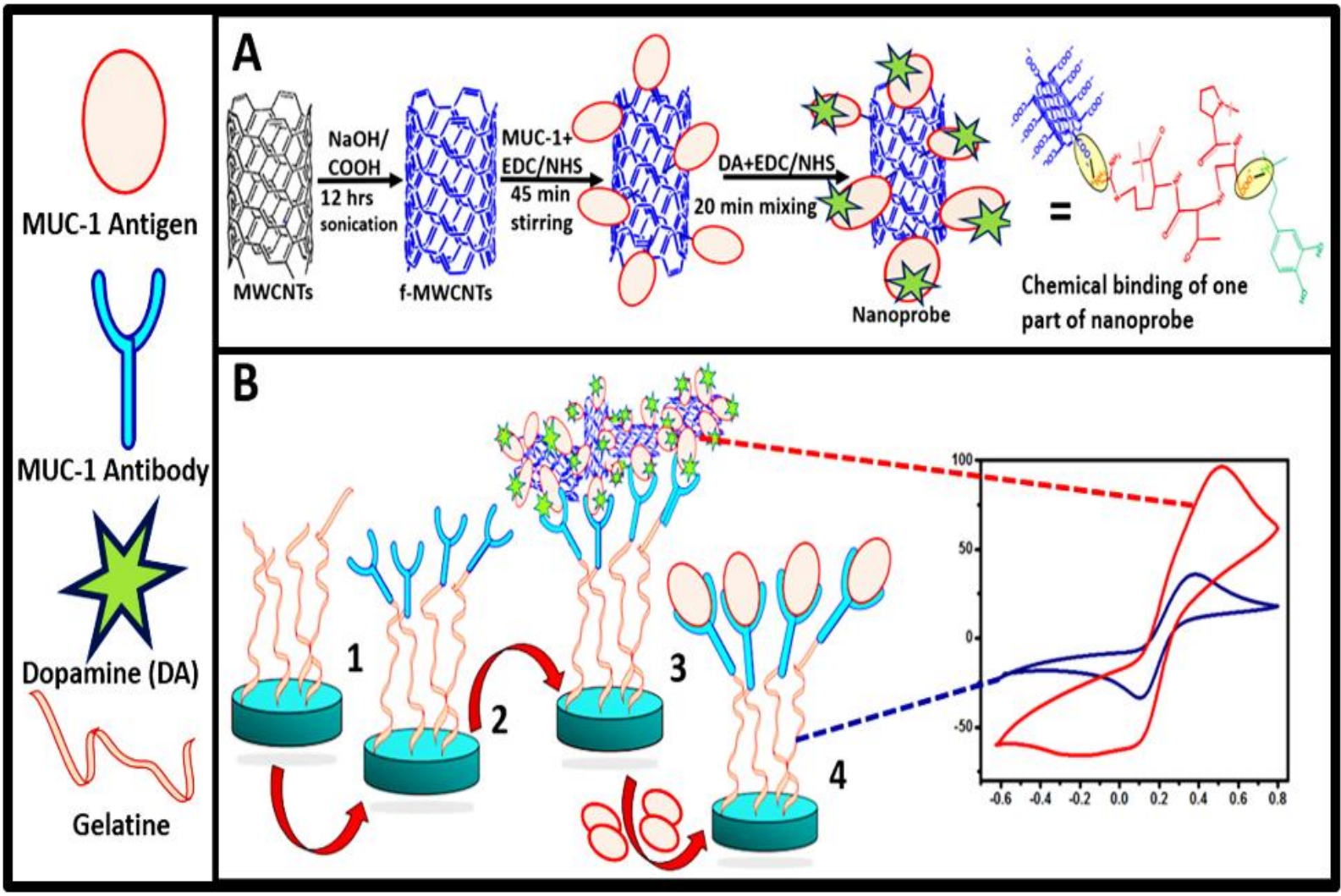

Scheme. 1. Schematic illustration of (A) different steps involved in the fabrication of nanoprobe, (B) Modification of working electrode and principle of direct competitive electrochemical immunosensor for breast cancer detection. (1) Electrooxidative grafting of gelatin on pencil electrode, (2) EDC/NHS attested binding of MUC-1 antibody, (3) Attachment of developed nanoprobe with modified electrode resulting in higher current signal, (4) Free MUC-1 replaced nanoprobe and resulting signal decreased in competitive assay.

The immunosensor was characterized both in ferri/ferro cyanide solution and PBS buffer.

Afterwards, when the immunosensor was used to recognize free MUC-1, a competitive process was carried out in PBS buffer. The proposed strategy is based on the direct competition between labelled and un-labelled antigen. The direct competition approach is well established detection mechanism in the literature. Both labelled and un-labelled antigens have equal binding tendencies, while the detection mechanism relies on the competition between both types of antigens. In the absence of free antigen, maximum signal intensity was observed while the presence of free antigen competed with the labelled one to bind with the immobilized antibody, thus decreasing the output signal. The decrease in response was proportional to the concentration of free analyte (antigen) and was employed for quantitative analysis of MUC-1. Since an electron donor (DA) was attached to the nanoprobe, a dramatic difference in current signal was observed in the absence and presence of free analyte. The immunosensor permitted to detect low level of MUC-1 in human serum samples and thus can be used for early diagnosis of breast cancer. 


\subsection{Characterization}

\section{$244 \quad$ 3.2.1 FTIR, UV-Vis, SEM, XRD and AFM analysis of nanoprobe}

245 FTIR spectra were used to evaluate and monitor the functional group changes during modification process of MWCNTs (Fig. 1A). No significant spectral bands appeared in case of MWCNTs, while a spectral peak at $1490 \mathrm{~cm}^{-1}$ was observed for C-H bending (a). However, in case of COOH-MWCNTs, several significant peaks appeared (b). Spectral peaks at $1202 \mathrm{~cm}^{-1}$ and 1490 to $1650 \mathrm{~cm}^{-1}$ were respectively assigned to $\mathrm{C}-\mathrm{O}-\mathrm{C}$ and $\mathrm{C}=\mathrm{C}$ bending modes. Spectral bands at 2850 to $2950 \mathrm{~cm}^{-1}$ represent C-H stretching vibrations. Another small spectral peak appeared at $3460 \mathrm{~cm}^{-1}$ for $\mathrm{OH}$-stretching of carboxylic group. Similarly, the spectral band at 2200 to $2300 \mathrm{~cm}^{-1}$ was assigned to $\mathrm{CO}_{2}$. However, upon incubation of MUC-1 protein (c), $\mathrm{C}=\mathrm{O}$ peak shifted to $1643 \mathrm{~cm}^{-1}$ and became broader due to amidecarbonyl stretching mode [27]. Small peaks at 1180, 1480 and $3430 \mathrm{~cm}^{-1}$ were assigned to aliphatic $\mathrm{C}-\mathrm{N}$ stretching, $\mathrm{N}-\mathrm{H}$ rocking and $\mathrm{N}-\mathrm{H}$ stretching vibrations, respectively [28]. A single absorption band appeared at $1636 \mathrm{~cm}^{-1}$, which was attributed to aromatic $(\mathrm{C}=\mathrm{C})$ of the
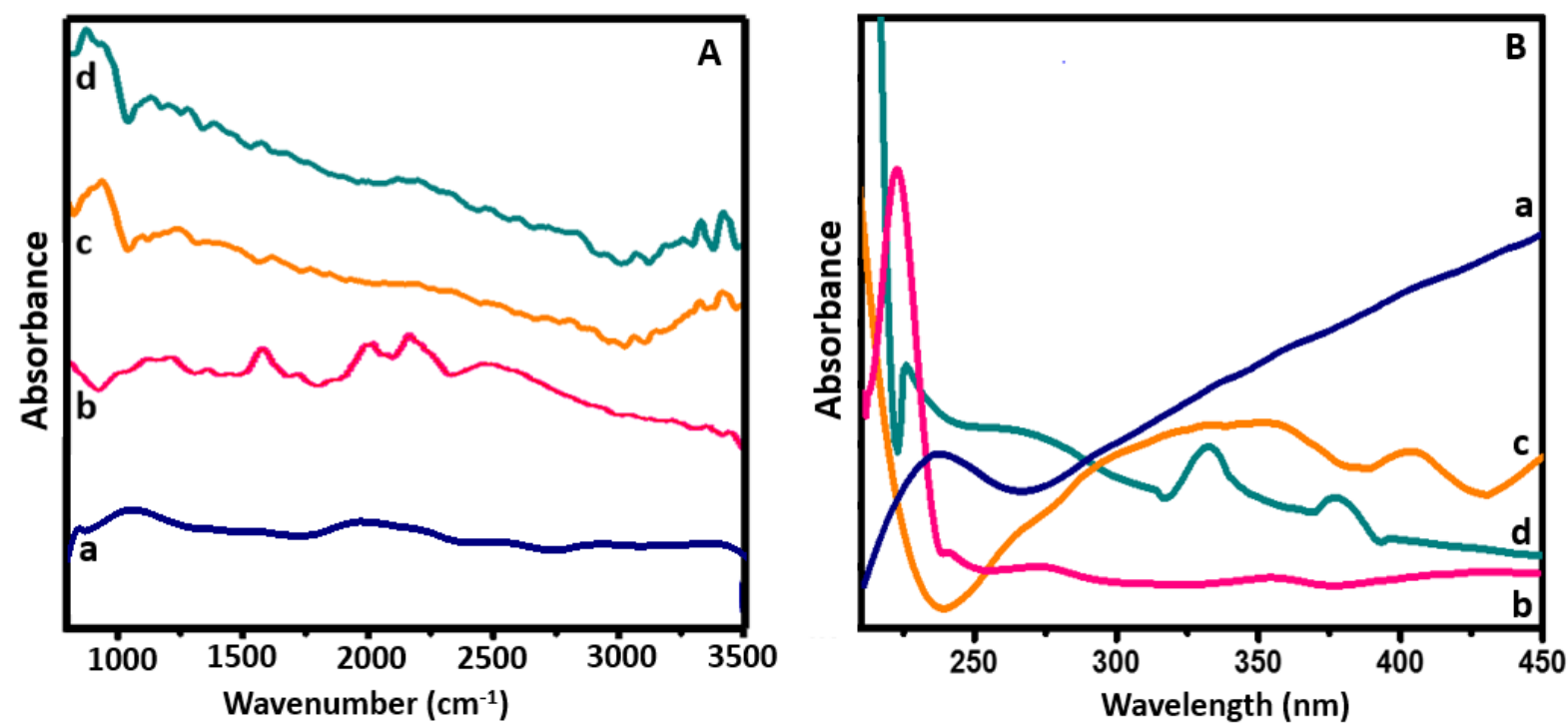

Fig. 1. (A) FTIR analysis and (B) UV-Vis spectra of a; MWCNTs, b) fMWCNTs, c) fMWCNTs/MUC-1 protein, d) fMWCNTs/MUC-1 protein/ DA.

Fig. 1.B shows the UV-Vis spectra of each modification step of MWCNTs during fabrication of electrochemical immunosensor. A characteristic peak of MWCNTs near $250 \mathrm{~nm}$ can be seen in Fig. 1B, a. The peak is in good agreement with the literature reporting characteristics of MWCNTs [30]. After acidic treatment (Fig. 1B, b), the transition absorption peaks near $250 \mathrm{~nm}$ became stronger with a red shift due to the electronic transition from $\mathrm{n} \rightarrow \pi^{*}$ of a nonbonding pair of electrons from carboxylic groups. It indicates that the functionalization 
process was efficient for MWCNTs to provide fMWCNTs. This red shift in the characteristic peak of MWCNTs corresponds to the presence of excessive carboxylic groups on the surface of fMWCNTs [31]. A characteristic peak at $260 \mathrm{~nm}$ was observed for MUC-1 as shown in Fig. 1B, c [32]. Finally, nanoprobe retained the characteristic absorption peaks of both MUC1 protein and DA at $368 \mathrm{~nm}$ [33], indicating the successful labelling of DA with nanoprobe (Fig. 1B, d).

The functionalization process was based on the attachment of organic moieties on the material surface. Therefore, a change in surface morphology via SEM and AFM could be used as an indicator to show the variation in surface nature upon different modification steps.

The SEM images at different stages of nanoprobe fabrication are displayed in Fig. 2. It can be observed from Fig. 2 that the MWCNTs have different surface morphology as compared to those of functionalized MWCNTs (fMWCNTs), fMWCNTs/MUC-1 protein and fMWCNTs/MUC-1/DA). It can also be observed from the micrographs that the surfaceroughness of MWCNTs increased after functionalization with COOH. Similarly, fMWCNTs became closely packed upon the addition of MUC-1 protein, making the surface appearance of MWCNTs as covered with cloudy clusters. After interaction of DA (Fig. 2D), the modified MWCNTs were found to be disaggregated.

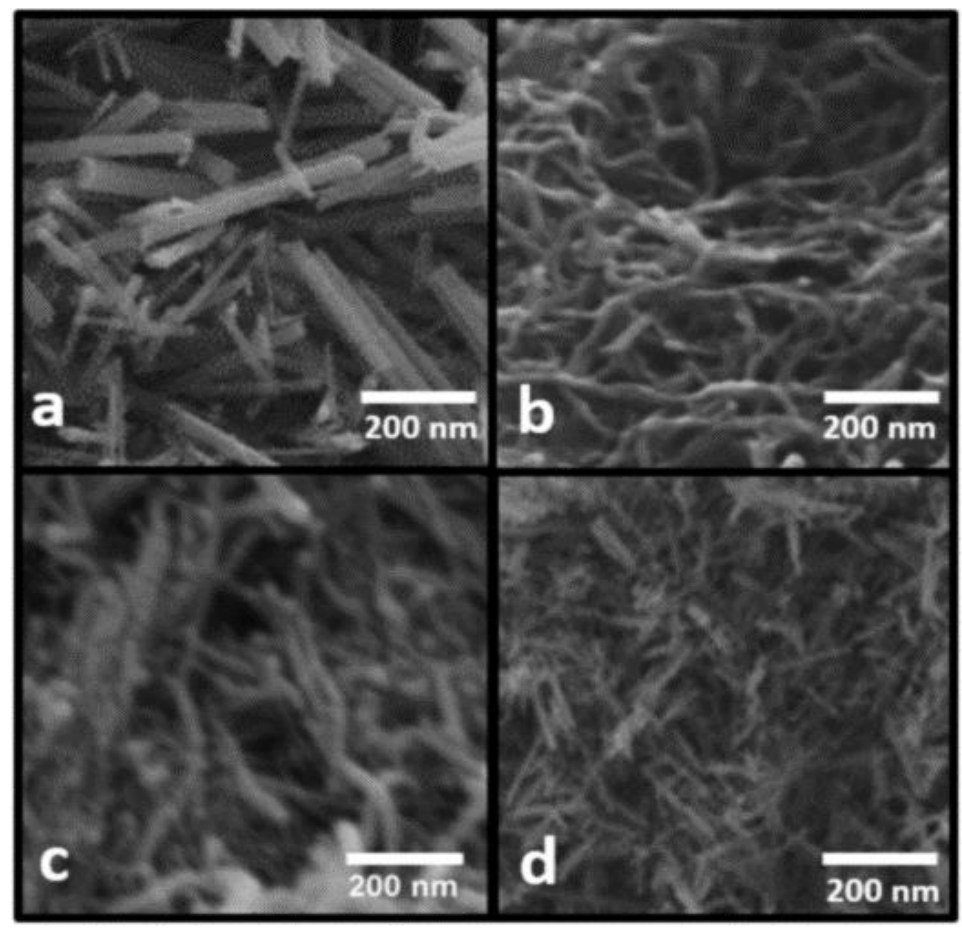

Fig. 2. SEM analysis of a; MWCNTs, b) fMWCNTs, c) fMWCNTs/MUC1 protein, d) fMWCNTs/MUC1 protein / DA. 
The XRD patterns for each fabrication step of nanoprobe were displayed in Fig. 3A. Typical peaks (002 and 100) of MWCNTs were obtained at $2 \Theta=26.68^{\circ}$ and $48^{\circ}$ respectively, which were in accordance with the reported literature. The intensity of 002 peak for fMWCNTs was increased as compared to pristine MWCNTs [34]. However, a decrease in the peak intensities was observed after the attachment of EDC/NHS treated MUC-1, with the appearance of additional peaks at $28.5^{\circ}$ and $46.7^{\circ}$, confirming the presence of MUC-1 on the surface of fMWCNTs [35]. XRD pattern of fMWCNTs/MUC-1 protein/DA, as shown in Fig. 3A, d depicted only one reduced peak of MWCNTs at $26^{\circ}$, while the other peaks were depressed due to the presence of DA [36].
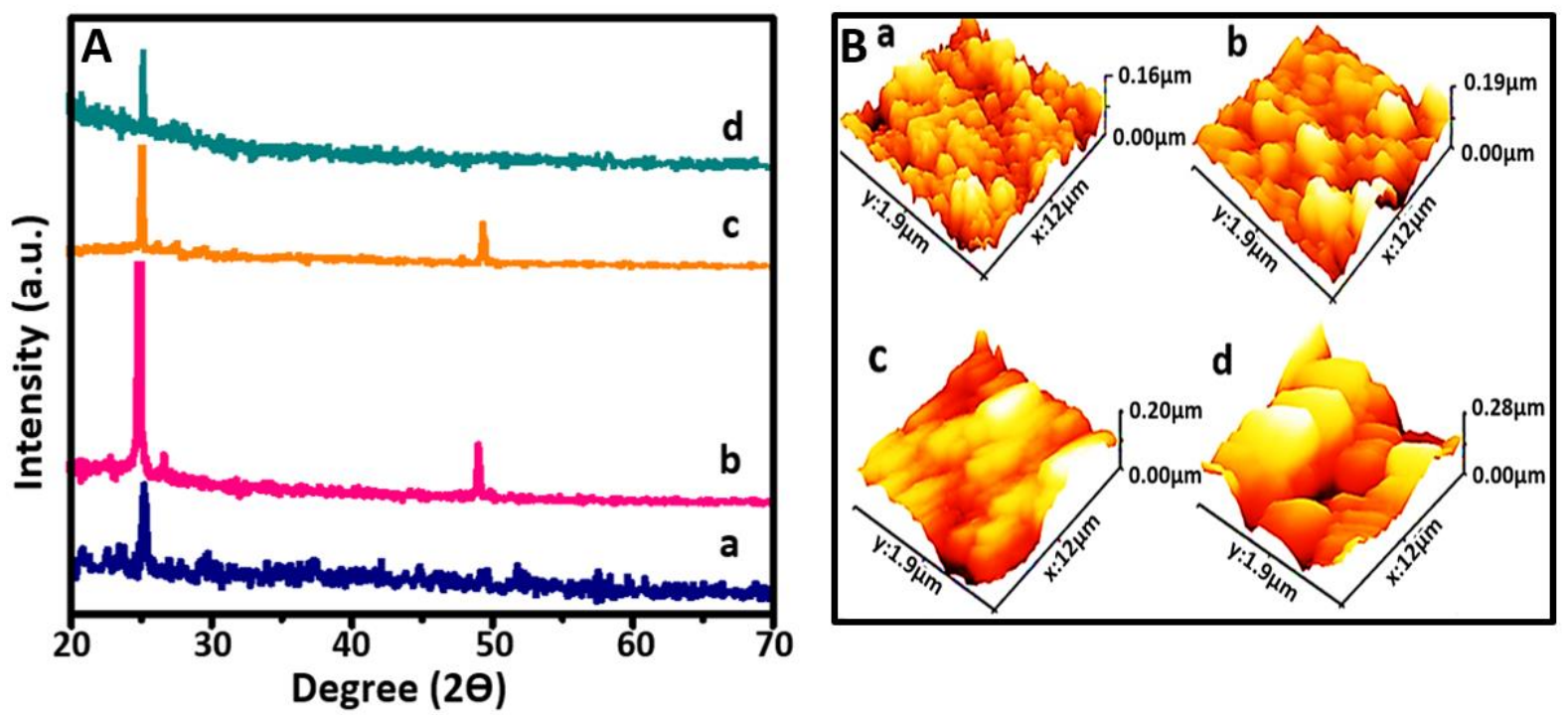

Fig. 3. (A) XRD analysis and (B) AFM topographs of step wise preparation of MUC-1 immunoprobe. a) MWCNTs, b) fMWCNTs, c) fMWCNTs/MUC-1 protein, d) fMWCNTs/MUC-1 protein/DA.

AFM was used for the investigation of surface morphology of nanoprobe. The topography images are given in Fig. 3B. Image (a) indicates the rough surface features of MWCNTs [37]. After functionalization process, the surface roughness was reduced with increased cluster formation. This decrease was attributed to the smoothing effect induced by f-MWCNTs [38]. Similarly, the immobilization of antibody increased the profile height with a changed surface morphology, thus indicating the attachment of large size molecules (antibody) on the surface of fMWCNTs (c). Finally, the DA attachment altered the height and surface of the topographical profile as shown in Fig. 3B, d.

\subsubsection{Characterization of modified electrode}

In Fig. 4A, the XRD images of modified electrode were presented. Peaks close to $28.1^{\circ}$ and $32.6^{\circ}$ were the characteristic peaks for carbon surface. After the immobilization of gelatin, the peaks were diminished. While the appearance of peak at $26.4^{\circ}$ proved the successful 
electro-oxidation of gelatin on the electrode surface. This XRD pattern reveals the amorphous structure of gelatin [39]. However, these peaks were decreased on the attachment of antibody, which occupied the carboxylic groups for amide bond formation. The addition of analyte further diminished the majority of the peaks, indicating the effective attachment of analyte on the transducer surface.
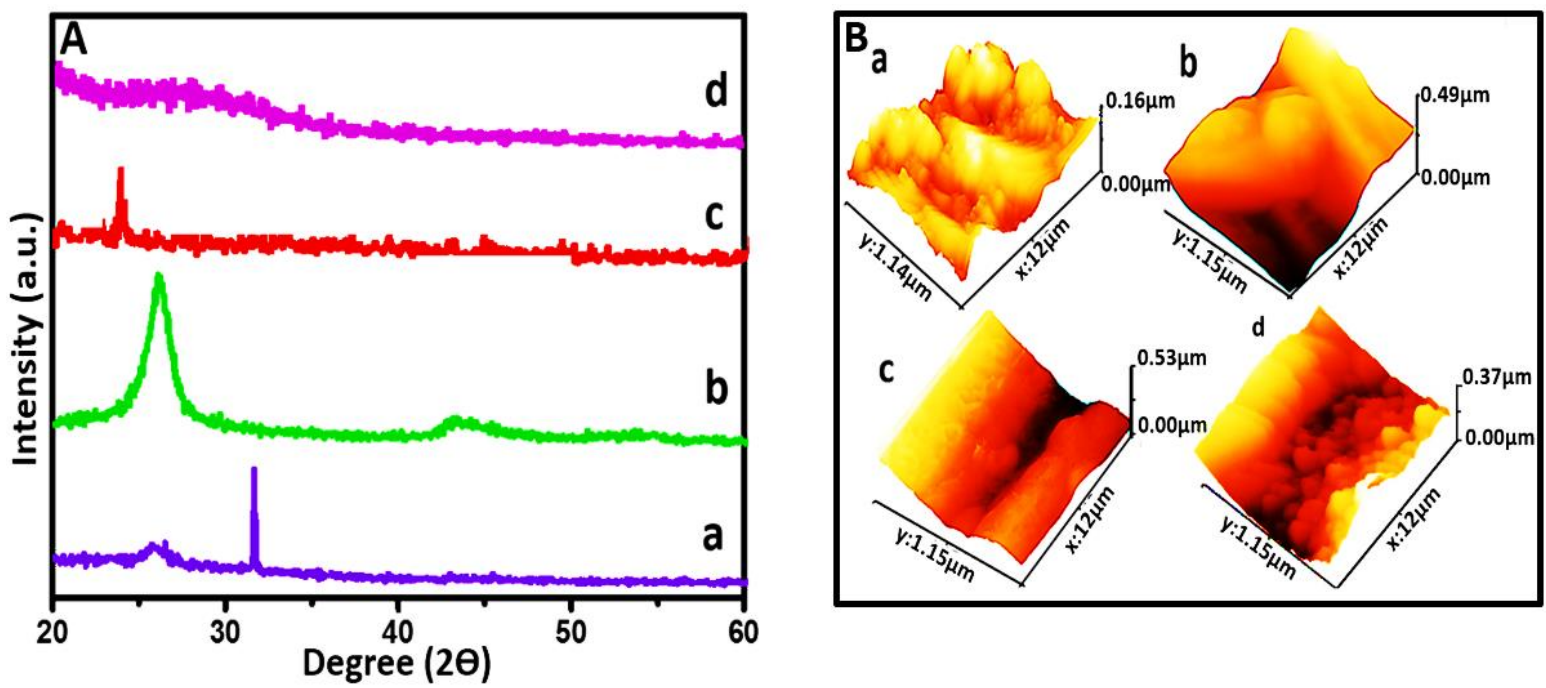

Fig. 4. (A) XRD and (B) AFM images of a) Bare electrode, b) Gelatin modified electrode, c) Gelatin modified electrode with MUC-1 antibody, d) Gelatin modified electrode with MUC-1 antibody + free MUC-1.

The stepwise investigation of electrode fabrication protocol was also performed using AFM topographic profiling. Fig. 4B, a represents the surface of bare electrode with a profile height of 0.00-0.16 $\mu \mathrm{m}$ and irregular trough and crust contrast. Gelatin grafting resulted in uniform topology with increased profile height, suggesting the effective immobilization of proteinic clusters, as shown in Fig. 4B, b. An improved smooth surface with increased profile height (Fig. 4B, c) was observed after the attachment of antibody, indicating the presence of bulky molecules on the modified electrode. Moreover, the specific attachment of analyte (MUC-1) resulted in the reversal of profile height and morphology, as illustrated in Fig. 4B, d. Such reversal of morphological features could be attributed to the breakage of clusters of antibody molecules [40].

\subsection{Electrochemical Characterization}

$\mathrm{CV}$ and EIS were performed for the characterization of each working step and different stages, involved in the fabrication of proposed immunosensor. CV and EIS are considered powerful tools to study the electrochemical characteristics of transducing surfaces. All electrochemical characterizations were carried out in the presence of $\left[\mathrm{Fe}(\mathrm{CN})_{6}\right]^{4-/ 3-}(1 \mathrm{mM})$ as an electro-active redox probe. This probe permits the recognition of high current response against the behaviour of electrochemically inert solution. In CV, differences in the peak 
currents (PC) and peak to peak separations were monitored to characterize each fabrication step of the electrochemical immunosensor. Similarly, EIS is also considered as a very effective electrochemical technique for surface modification characterization. The Nyquist plot with a semicircle portion at higher frequencies corresponds to the electron transfer resistance. Impedance spectra (Nyquist plots) for each surface modification step were recorded using the Randles equivalent circuit. The circuit consisted of ohmic electrolyte resistance $\left(R_{\mathrm{s}}\right)$, the electron-transfer resistance $\left(R_{\mathrm{et}}\right)$, the Warburg impedance element $\left(\mathrm{Z}_{\mathrm{w}}\right)$ resulting from the diffusion of ions from the bulk of the electrolyte to the interface, and the constant phase element. The $\mathrm{R}_{\mathrm{et}}$ depends on the insulating feature at the electrode/electrolyte interface and represents facial properties of the surface. $R_{\text {et }}$ is the useful parameter to evaluate interfacial properties. Therefore, $\mathrm{R}_{\mathrm{et}}$ was considered to monitor the changes on the electrode interface at each fabrication step for the designed immunosensor.

\subsubsection{Characterization of nanoprobe assembly}
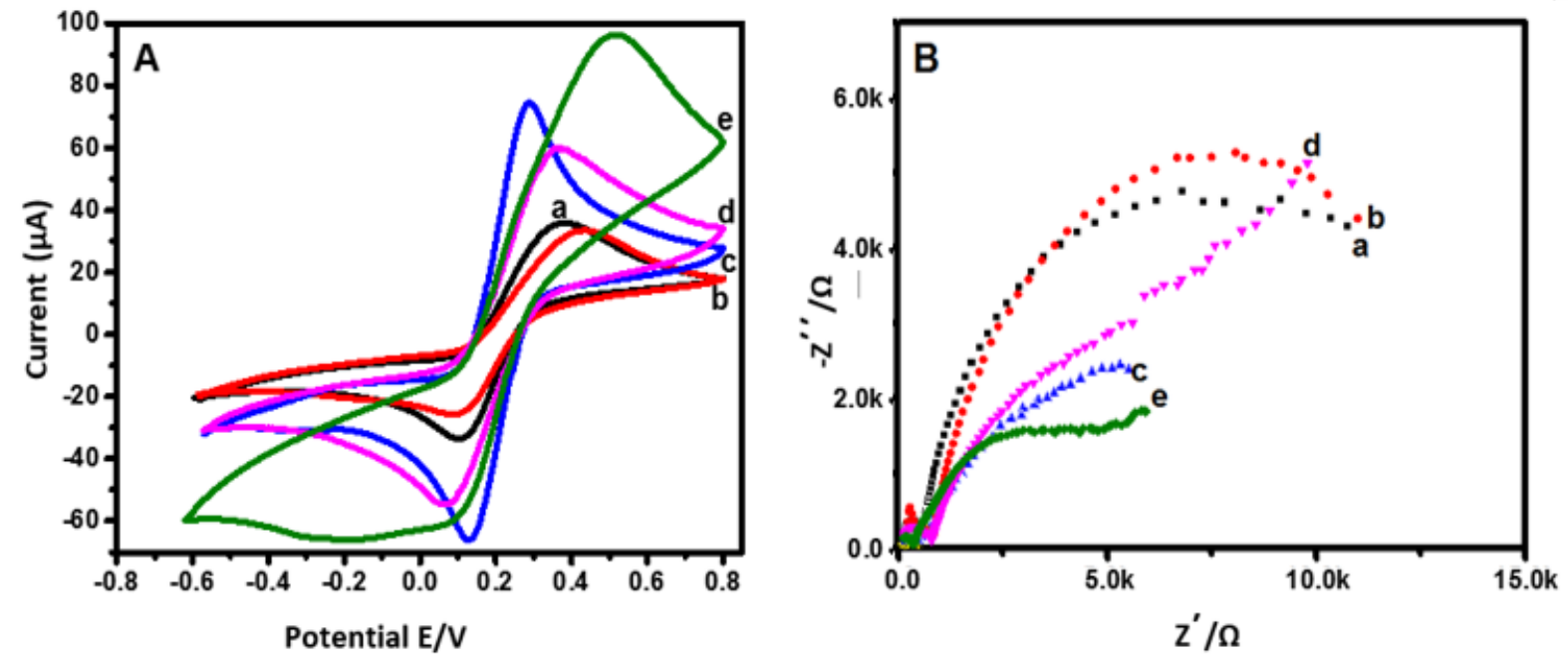

Fig. 5. (A) Cyclic voltammograms and (B) Electrochemical Impedance spectra of different steps involved in nanoprobe preparation; a. Bare PGE, b. MWCNTs, c. fMCNTs/EDC-activated, d. fMCNTs/EDCactivated/MUC-1 protein, e. fMCNTs/EDC-activated/ MUC-1 protein/DA.

Cyclic voltammograms for all fabrication steps involved in the formation of nanoprobe are shown in Fig. 5A. The representative anodic and cathodic peaks were observed for (a) Bare PGE, (b) MWCNTs, (c) fMWCNTs/EDC-activated, (d) fMWCNTs/EDC-activated/MUC-1 protein, and (e) fMWCNTs/EDC-activated/ MUC-1 protein/DA. A characteristic redox peak of bare PGE with the anodic and cathodic peak current was observed. The presence of MWCNTs resulted in a decrease in the current with increased electron transfer resistance $\left(\mathrm{R}_{\mathrm{et}}\right)$. After the formation of fMWCNTs/EDC-activated PGE, the $\mathrm{R}_{\mathrm{et}}$ between electrode surface and activated fMWCNTs was reduced due to the succinimide moiety introduced by 
EDC-activation. After the immobilization of MUC-1 protein, the negatively charged phosphate groups resulted in the higher $\mathrm{R}_{\mathrm{et}}$ value. However, upon addition of DA, an increased CV-response was observed. Basically, well assembled DA on the nanoprobe facilitated the flow of electrons [41]. The trend of the impedimetric response of all the fabrication steps was found to be the analogue of their CV response as can be evidenced in the Fig. 5A and 5B.

\subsubsection{Characterization of transducer surface fabrication}

Electro-oxidation of gelatin was performed in acetate buffer $(\mathrm{pH}=5)$. A representative first scan of oxidation process is shown in Fig. 6A. After deposition of gelatin, the modification steps were characterized in the presence of $1 \mathrm{mM}$ redox couple $\left[\mathrm{Fe}(\mathrm{CN})_{6}\right]^{4-/ 3-}$. The $\mathrm{CV}$ current of the bare electrode enhanced (approximately 2-folds) after electrochemical oxidation of gelatin on PGE surface while peak shifted to the higher potential, as shown in Fig. 6B, b.
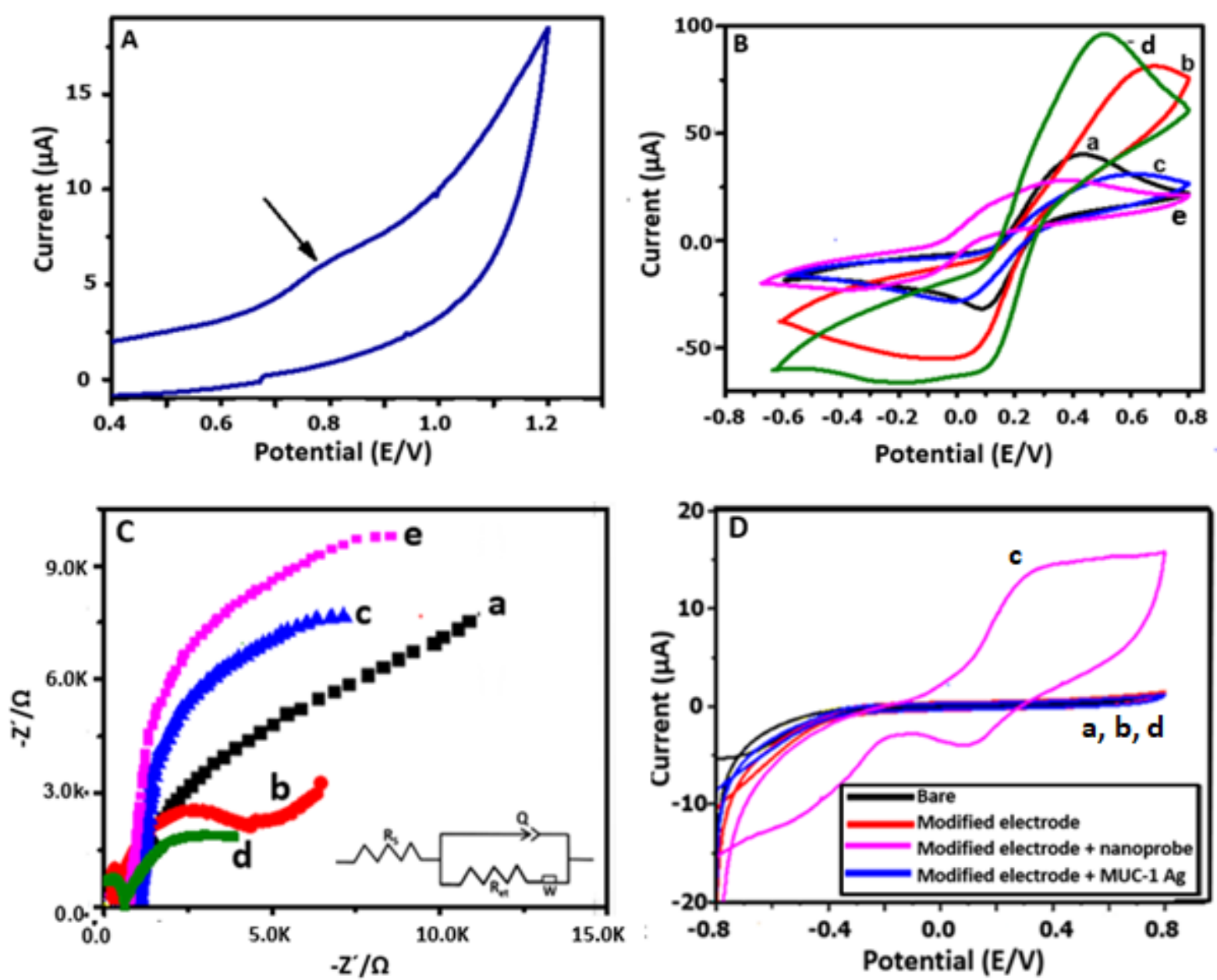

Fig. 6. (A) Characteristic CV curve for electro-oxidation of gelatin (first cycle) on PGE-surface $(2.5 \mathrm{mg} / \mathrm{mL}$ in Acetate buffer $\mathrm{pH}=5$ ). (B) Cyclic Voltammograms and (C) Electrochemical impedance of different steps involved in the fabrication of immunosensor; a. Bare, b. Bare/gelatin, c. Bare/gelatin/antibody, d. 
Bare/gelatin/antibody/nanoprobe, e. Bare/gelatin/antibody/nanoprobe/free MUC-1. (D) Cyclic Voltammograms of immunosensor in PBS to demonstrate the working mechanism; a. Bare, b. gelatin, c. gelatin/nanoprobe, d. gelatin/nanoprobe/MUC-1 Ag.

With gelatin grafting, a good peak to peak separation was observed. These electrochemical changes suggested an increased electron transfer rate between modified electrode surface and the electrolyte solution. The EDC/NHS treated MUC-1 antibody immobilization resulted in a reduction of electron transfer, showing a further peak shifting towards higher potential as represented in Fig. 6B, c. The immobilization of nanoprobe resulted in a very prominent redox peak (Fig. 6B, d). However, upon incubation of analyte (MUC-1), a clear decrease in peak current was observed (Fig. 6B, e). This enhanced signal in case of nanoprobe was mainly contributed by DA, which is an efficient electron-donor. It is note-worthy that the electron donor signal probes can be attached precisely to the target analyte for signal amplification [41]. The maximum surface of fMWCNTs was covered by MUC-1, hindering the attachment of DA molecules on the surface of fMWCNTs. Moreover, the DA was used as an electron donor and the intensity of current signal was dependent on the amount of attached DA. DA has been employed as a probe to donate electrons for signal amplification in the construction of the electrochemical biosensors [42]. It can also be observed from the Fig. 6 that the combination of DA and MUC-1 altered the nature of peak current, which could be attributed to the high electrical conductivity of DA [43]. When MUC-1 antigen competed with the MUC-1 nanoprobe containing DA, the peak current was decreased. Additionally, the antigens acted as an insulator and subsequently reduced the electron transfer rate [44]. This could be attributed to the antibody-antigen complex on the surface of the modified electrode $[20]$.

Similarly, Fig. 6D represents the electrochemical response of PGE at different modification steps in PBS. A characteristic redox peak of DA was observed in the presence of DA labelled MUC-1 (Fig. 6D, c), while the given characteristic peak was significantly decreased upon competition between free and DA labelled MUC-1, as shown in the Fig. 6D, d. This further demonstrates the working mechanism of fabricated immunosensor. Similarly, bare and gelatin modified electrodes did not show any response.

\subsection{Competition assay for MUC-1 protein}

Prior to perform competition assay, different experimental conditions were optimized. The detail of the experimental optimization is provided in the supporting information (SI). To validate the immobilization method, direct competitive immunoassays were performed for MUC-1 analysis using optimized experimental parameters. The assays were relied on the 
competition between the free MUC-1 and labelled MUC-1 nanoprobe. When the system was tested without free MUC-1 by CV, a current signal of $98.9 \mu \mathrm{A}$ was obtained as shown in Fig. 6B.This current was high enough to carry out the competition step and measure the lower current intensities (Fig. 7A). The proposed strategy was based on the direct competition between labelled and un-labelled antigen. The direct competition approach is well established detection mechanism in the literature. Both labelled and un-labelled antigens have equal binding tendencies, while the detection mechanism relies on the competition between both types of antigens. In the absence of free antigen, a maximum signal was observed while the presence of free antigen competed with the labelled one to bind with the immobilized antibody, thus decreasing the output signal. The decrease in response was proportional to the concentration of free analyte (antigen), hence, utilized for its quantitative analysis. For the higher concentrations (473.6 and $940 \mathrm{U} / \mathrm{mL}$ ), the change in current response was difficult to be observed due to saturation point. The calibration curve obtained with electrochemical immunosensor is shown in Fig. 7B. Due to experimental error (5\%), the LOD was defined as the MUC-1 concentration, which corresponds to the $85 \%$ of MUC-1 binding depending on the maximum standard deviation value. The calibration curve (Fig. 7B) was fitted by sigmoidal logistic four parameter-equation $\mathrm{y}=\mathrm{a}_{2}+\left[\mathrm{a}_{1}-\mathrm{a}_{2} / 1+\left(\mathrm{x} / \mathrm{x}_{0}\right)^{p}\right]$ using Origin Pro- 8 SR0 software, in which $\mathrm{a}_{2}$ and $\mathrm{a}_{1}$ are the maximum and minimum values respectively, and $\mathrm{x}^{0}$ and $p$ are the $\mathrm{x}$ value at the inflection point and the slope of inflection point accordingly. With the help of equation, percentage binding was evaluated depending upon the maximum standard deviation value. The lower percentage binding (less than $100 \%$ ) could be linked with the high number of the washing steps that might cause leaching of excessive antibodies out of the electrode surface. The correlation coefficient R, LOD and IC50 values were found 436 to be $0.95,0.01 \mathrm{U} / \mathrm{mL}$ and $7.4 \mathrm{U} / \mathrm{mL}$ respectively, from regression equation.
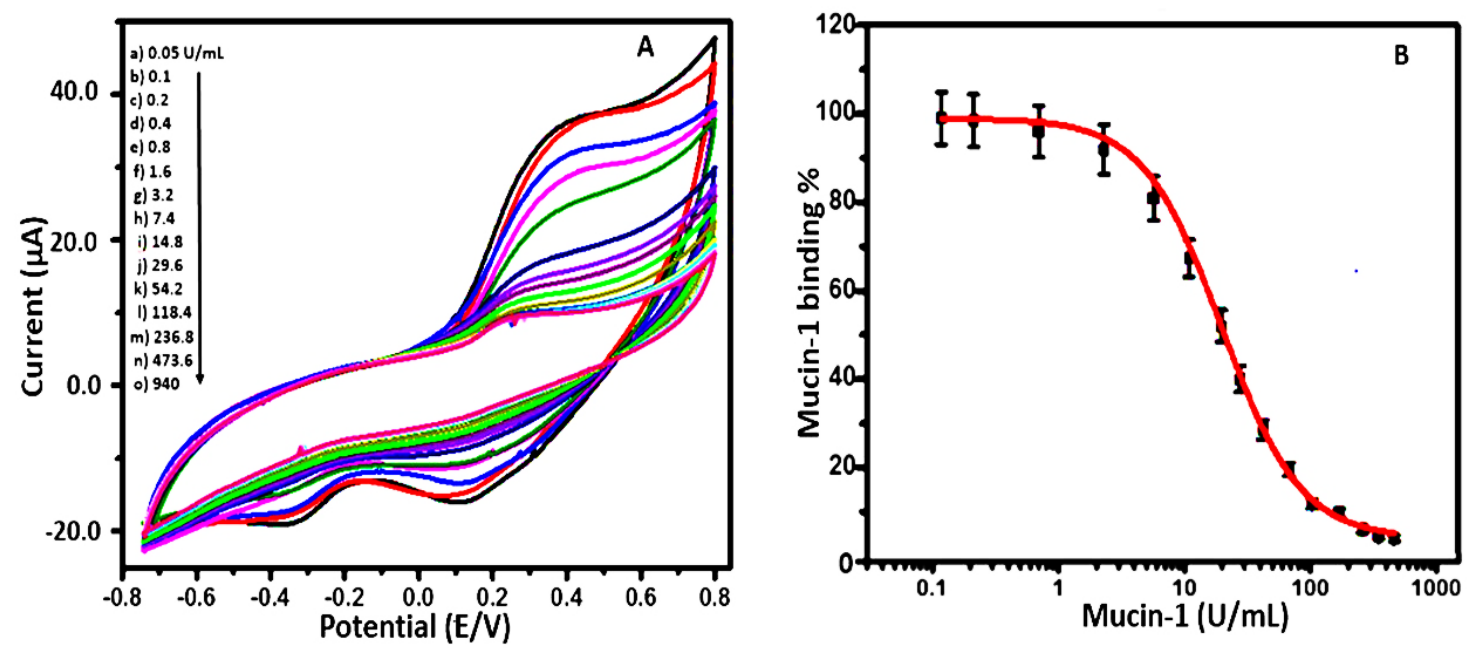
Fig. 7. Variation of CV with increasing concentration of free MUC-1 for competition assay (A) and standard curve for proposed assay (B). Experimental conditions: Gelatin concentration $=0.1 \mathrm{M}$, antibody concentration= $0.25 \mathrm{U} / \mathrm{mL}$, antibody incubation time $=30 \mathrm{~min}$, nanoprobe concentration $=25 \mu \mathrm{L}$, nanoprobe incubation time $=$ $15 \mathrm{~min}$, DA concentration $=0.1 \mathrm{M}, \mathrm{pH}$ of buffer $=7.2$.

Table 1 presents a comparison between the given electrochemical immunosensor and the existing literature reports for the detection of cancer biomarker.

Table 1. A comparison of present work with the published literature reports for the detection of MUC-1.

\begin{tabular}{|c|c|c|c|c|c|}
\hline No. & $\begin{array}{l}\text { Material } \\
\text { Used }\end{array}$ & $\begin{array}{l}\text { Detection } \\
\text { Method }\end{array}$ & $\begin{array}{l}\text { LOD } \\
(\mathrm{U} / \mathrm{m} \\
\mathrm{L})\end{array}$ & $\begin{array}{l}\text { Linear } \\
\text { Range } \\
(\%)\end{array}$ & Ref. \\
\hline 1 & $\begin{array}{l}\mathrm{Au} / \mathrm{ZnO} \text { thin film } \\
\text { surface }\end{array}$ & $\begin{array}{l}\text { Plasmon Resonance } \\
\text { Based }\end{array}$ & 0.025 & $1-40$ & [45] \\
\hline 2 & $\begin{array}{l}\mathrm{COOH} \\
\text { graphene oxide }\end{array}$ & $\begin{array}{l}\text { Disposable } \\
\text { electrochemical } \\
\text { immunosensor }\end{array}$ & 0.04 & $0.1-2$ & [46] \\
\hline 3 & $\begin{array}{l}\text { Coated } \\
\text { Polymethylmethacr } \\
\text { ylate }\end{array}$ & $\begin{array}{l}\text { Kinetic-exclusion } \\
\text { analytical } \\
\text { technology }\end{array}$ & 0.21 & $0.3-20$ & [47] \\
\hline 4 & Pt nanoclusters & $\begin{array}{l}\text { Enzyme-linked } \\
\text { Immunosensor }\end{array}$ & 0.04 & $0.1-160$ & [48] \\
\hline 5 & $\begin{array}{l}\text { DA/MUC- } \\
\text { 1/fMWCNT }\end{array}$ & $\begin{array}{l}\text { Direct competitive } \\
\text { immunosensor }\end{array}$ & 0.01 & $\begin{array}{l}0.05- \\
940\end{array}$ & $\begin{array}{l}\text { Present } \\
\text { work }\end{array}$ \\
\hline
\end{tabular}

The above comparison demonstrated the advantages of developed immunosensor over the reported methods in terms of lower LOD and linear range. The lower LOD could be attributed to the direct immobilization through covalent linking that increased the accessibility of free MUC-1 to the antibody [49].

\subsection{Stability and Reproducibility}

In order to evaluate the stability, the immunosensor was stored at $4{ }^{\circ} \mathrm{C}$ after every use. The response of the immunosensor did not show any significant change over a period of two weeks, indicating the extended stability of the immunosensor. Furthermore, reproducibility of the immunosensor was also assessed. For this purpose, five immunosensors were designed independently under the optimized experimental conditions to detect the MUC-1 IC50 concentration $(7.4 \mathrm{U} / \mathrm{mL})$. The relative standard deviation (RSD) of the peak current difference was about $1.52 \%$, indicating good reproducibility of the proposed immunosensor (Fig. 8.). 

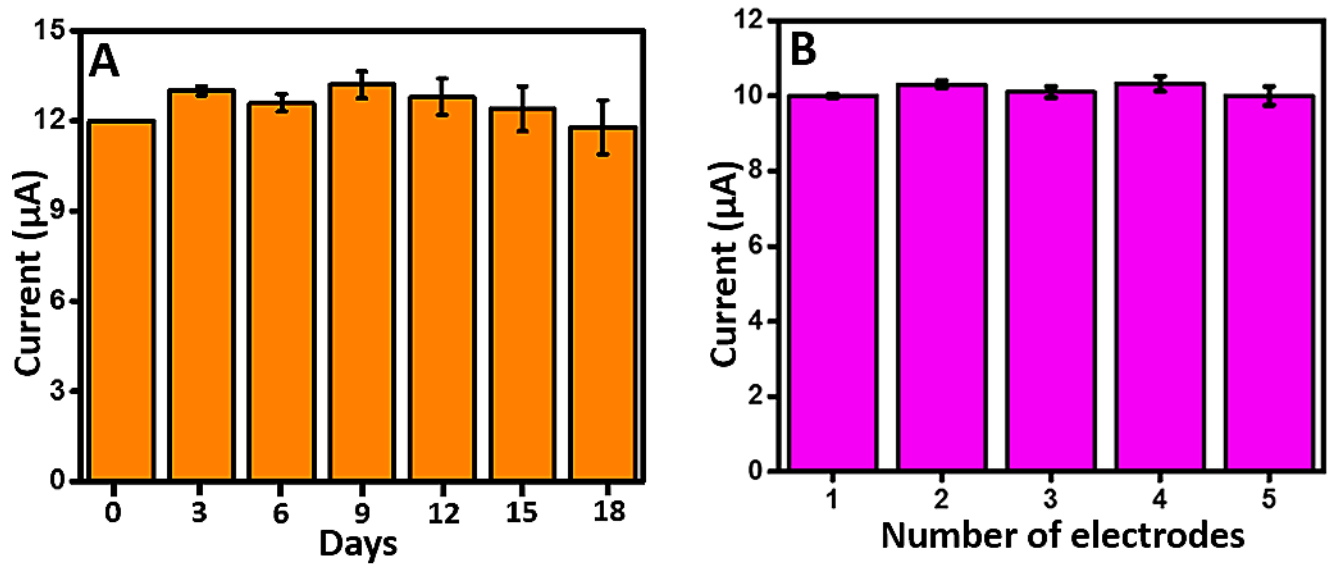

Fig. 8. (A) Stability and (B) Reproducibility of the proposed electrochemical immunosensor for the detection of $10 \mathrm{nM}$ MUC1.

\subsection{Recovery and spiked sample analysis}

In order to verify the clinical applicability of our proposed immunosensor for MUC-1 detection, human serum samples (taken from Shaukat Khanum Memorial Cancer Hospital \& Research Center, Lahore Pakistan) were spiked with three different concentrations of MUC-1 (0.1, 14.8 and $473.6 \mathrm{fU} / \mathrm{mL})$. Antibody immobilized gelatin-PGE modified electrodes were incubated with above mentioned concentrations at optimized experimental conditions with same protocol as described for standard MUC-1 analysis. Assays were performed in triplicate. Good recoveries (93.5-95\%) were obtained with R.S.D \% in the range of (4.6-6). The percentage recoveries are summarised in table 2 . These results proved the clinical applicability of the immunosensor for complex biological systems.

Table 2. Recovery percentages obtained for real sample analysis against various concentrations of MUC-1 using proposed immunosensor.

\begin{tabular}{|c|c|c|c|c|c|c|}
\hline No. & $\begin{array}{l}\text { MUC-1 added } \\
(\mathrm{U} / \mathrm{mL})\end{array}$ & $\begin{array}{l}\text { MUC-1 } \\
(\mathrm{U} / \mathrm{mL})\end{array}$ & found & R.S.D \% & R.E \% & $\mathbf{R} \%$ \\
\hline 1 & 0.1 & 0.06 & & 6 & 6.5 & 93.5 \\
\hline 2 & 14.8 & 12.9 & & 4.6 & 5 & 95 \\
\hline 3 & 473.6 & 452 & & 5 & 5.5 & 94.5 \\
\hline
\end{tabular}

R.S.D=Relative standard deviation, R.E $=$ Relative Error, $\mathrm{R}=$ Recovery

\subsection{Specificity of the Immunosensor}

Selectivity and specificity are important parameters to validate the practical applicability of the immunosensor. Therefore, by performing control experiment with non-specific binding proteins such as BSA, FBS and NS1, the specificity of designed immunosensor was evaluated. Fig. 9 illustrates the percentage (\%) binding response of the antibody immobilized gelatin-PGE modified electrode upon incubation with non-specific (FBS, BSA, NS1) as well 
as structural analogue (MUC-2) proteins. It is evident from Fig. 9 that the percentage binding response values for nonspecific proteins were considerably lower than MUC-1. However, MUC-2 showed higher response in comparison to non-specific binding proteins but much lesser than MUC-1. These results proved that the effect of non-specific proteins was insignificant on MUC-1 detection and the proposed immunosensor had sufficient specificity towards MUC-1 protein.

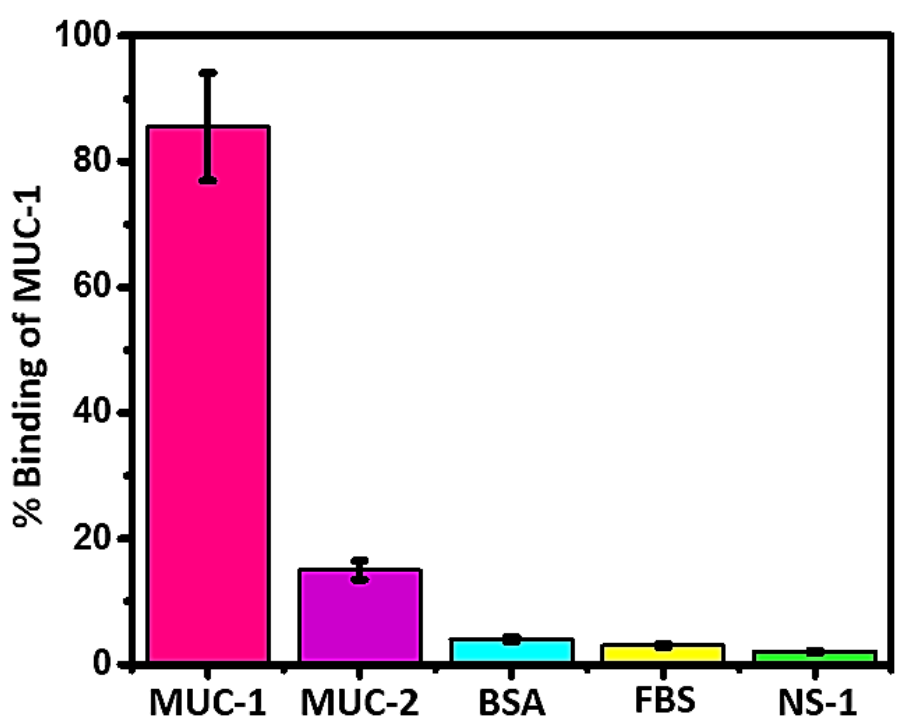

Fig. 9. Specificity of the proposed immunosensor for MUC-1 analysis.

\section{Conclusion}

In this study, a new, simple and inexpensive strategy for the detection of MUC-1 has been developed. Modification of fMWCNTs with Ag and DA provided a highly sensitive nanoprobe, which offered distinct advantages over the already reported electro-active labels in literature. On the other hand, modification of the PGE with GE facilitated to overcome the problem of biological damages and toxicity imposed by non-biological transducing materials. Both the above mentioned modifications provided an ideal and conductive platform using amino-carboxy-surface chemistry of gelatin and fMWCNTs. Compared to other reported electrochemical immunosensors for the detection of MUC-1, the proposed immunosensor functioned well over a wide linear range between $0.05-940 \mathrm{U} / \mathrm{mL}$, anda low LOD of 0.01 $\mathrm{U} / \mathrm{mL}$. Moreover, the designed immunosensor offers significant potential for widespread applications in the field of clinical diagnostics and can easily be extended to the development of other types of bio-receptor surfaces based on aptamers/antibodies for the detection of other analytes. This could not only be useful for rapid detection but also for the monitoring of the progression of disease process, which is a far bigger challenge than detection. 
506 This work was the part of project supported by HEC (Higher Education Commission), 507 Pakistan and PERIDOT, France; No. 2-3/HEC/R\&D/PERIDOT/2016. Authors acknowledge 508 the funding for this research provided by Higher Education Commission, Pakistan (5411509 FedralNRPU-R\&D-HEC-2016).

\section{Conflict of interest}

511 Authors declare no conflict of interest.

\section{References}

513 [1] S. Yang, M. You, F. Zhang, Q. Wang, P. He, A sensitive electrochemical aptasensing platform 514 based on exonuclease recycling amplification and host-guest recognition for detection of breast cancer biomarker HER2, Sensors and Actuators B: Chemical, 258(2018) 796-802.

[2] A.B. Chinen, C.M. Guan, J.R. Ferrer, S.N. Barnaby, T.J. Merkel, C.A. Mirkin, Nanoparticle probes for the detection of cancer biomarkers, cells, and tissues by fluorescence, Chemical reviews, 115(2015) 10530-74.

[3] J. Zhang, Y. Liu, X. Wang, Y. Chen, G. Li, Electrochemical assay of $\alpha$-glucosidase activity and the inhibitor screening in cell medium, Biosensors and Bioelectronics, 74(2015) 666-72.

[4] S.K. Arya, P. Zhurauski, P. Jolly, M.R. Batistuti, M. Mulato, P. Estrela, Capacitive aptasensor based on interdigitated electrode for breast cancer detection in undiluted human serum, Biosensors and Bioelectronics, 102(2018) 106-12.

[5] Y. Wan, W. Deng, Y. Su, X. Zhu, C. Peng, H. Hu, et al., Carbon nanotube-based ultrasensitive multiplexing electrochemical immunosensor for cancer biomarkers, Biosensors and Bioelectronics, 30(2011) 93-9.

[6] V. Mani, B.V. Chikkaveeraiah, V. Patel, J.S. Gutkind, J.F. Rusling, Ultrasensitive immunosensor for cancer biomarker proteins using gold nanoparticle film electrodes and multienzyme-particle amplification, ACS Nano, 3(2009) 585-94.

[7] C. Baj-Rossi, G.D. Micheli, S. Carrara, Electrochemical detection of anti-breast-cancer agents in human serum by cytochrome P450-coated carbon nanotubes, Sensors, 12(2012) 6520-37.

[8] E. Darrigues, V. Dantuluri, Z.A. Nima, K.B. Vang-Dings, R.J. Griffin, A.R. Biris, et al., Raman spectroscopy using plasmonic and carbon-based nanoparticles for cancer detection, diagnosis, and treatment guidance. Part 2: Treatment, Drug metabolism reviews, 49(2017) 253-83.

[9] J. Xue, T. Wu, Y. Dai, Y. Xia, Electrospinning and electrospun nanofibers: Methods, materials, and applications, Chemical reviews, 119(2019) 5298-415.

[10] L. Singh, H.G. Kruger, G.E. Maguire, T. Govender, R. Parboosing, The role of nanotechnology in the treatment of viral infections, Therapeutic advances in infectious disease, 4(2017) 105-31.

[11] F. Karimi, S. Alizadeh, H. Alizadeh, Immunogenicity of multi-walled carbon nanotubes functionalized with recombinant protective antigen domain 4 toward development of a nanovaccine against anthrax, Journal of Drug Delivery Science and Technology, 47(2018) 322-9.

[12] N. Xia, L. Zhang, Q. Feng, D. Deng, X. Sun, L. Liu, Amplified voltammetric detection of tyrosinase and its activity with dopamine-gold nanoparticles as redox probes, (2013).

[13] R. Zhang, Z. Fan, Nitrogen-doped carbon quantum dots as a "turn off-on" fluorescence sensor based on the redox reaction mechanism for the sensitive detection of dopamine and alpha lipoic acid, Journal of Photochemistry and Photobiology A: Chemistry, 392(2020) 112438. 
[14] X. Ji, G. Palui, T. Avellini, H.B. Na, C. Yi, K.L. Knappenberger Jr, et al., On the pH-dependent 548 quenching of quantum dot photoluminescence by redox active dopamine, Journal of the American 549 Chemical Society, 134(2012) 6006-17.

550 [15] F. Chen, Q. Wu, D. Song, X. Wang, P. Ma, Y. Sun, Fe304@ PDA immune probe-based signal and Surfaces B: Biointerfaces, 177(2019) 105-11.

[16] L. Jothi, S. Neogi, S.k. Jaganathan, G. Nageswaran, Simultaneous determination of ascorbic acid, dopamine and uric acid by a novel electrochemical sensor based on N2/Ar RF plasma assisted graphene nanosheets/graphene nanoribbons, Biosensors and Bioelectronics, 105(2018) 236-42.

[17] S.N. Topkaya, Gelatin methacrylate (GeIMA) mediated electrochemical DNA biosensor for DNA hybridization, Biosensors and Bioelectronics, 64(2015) 456-61.

[18] A.P. Periasamy, Y.-J. Chang, S.-M. Chen, Amperometric glucose sensor based on glucose oxidase immobilized on gelatin-multiwalled carbon nanotube modified glassy carbon electrode, Bioelectrochemistry, 80(2011) 114-20.

[19] F. Mollarasouli, S. Kurbanoglu, S.A. Ozkan, The role of electrochemical immunosensors in clinical analysis, Biosensors, 9(2019) 86.

[20] M. Hasanzadeh, S. Rahimi, E. Solhi, A. Mokhtarzadeh, N. Shadjou, J. Soleymani, et al., Probing the antigen-antibody interaction towards ultrasensitive recognition of cancer biomarker in adenocarcinoma cell lysates using layer-by-layer assembled silver nano-cubics with porous structure on cysteamine caped GQDs, Microchemical Journal, 143(2018) 379-92.

[21] L. Farzin, M. Shamsipur, Recent advances in design of electrochemical affinity biosensors for low level detection of cancer protein biomarkers using nanomaterial-assisted signal enhancement strategies, Journal of Pharmaceutical and Biomedical Analysis, 147(2018) 185-210.

[22] S. Centi, G. Messina, S. Tombelli, I. Palchetti, M. Mascini, Different approaches for the detection of thrombin by an electrochemical aptamer-based assay coupled to magnetic beads, Biosensors and Bioelectronics, 23(2008) 1602-9.

[23] A. Hayat, L. Barthelmebs, A. Sassolas, J.-L. Marty, An electrochemical immunosensor based on covalent immobilization of okadaic acid onto screen printed carbon electrode via diazotizationcoupling reaction, Talanta, 85(2011) 513-8.

[24] A.K. Trilling, J. Beekwilder, H. Zuilhof, Antibody orientation on biosensor surfaces: a minireview, Analyst, 138(2013) 1619-27.

[25] H.-J. Um, M. Kim, S.-H. Lee, J. Min, H. Kim, Y.-W. Choi, et al., Electrochemically oriented immobilization of antibody on poly-(2-cyano-ethylpyrrole)-coated gold electrode using a cyclic voltammetry, Talanta, 84(2011) 330-4.

[26] A.K. Trilling, M.M. Harmsen, V.J.B. Ruigrok, H. Zuilhof, J. Beekwilder, The effect of uniform capture molecule orientation on biosensor sensitivity: Dependence on analyte properties, Biosensors and Bioelectronics, 40(2013) 219-26.

[27] L. Qiao, B. Lv, X. Feng, C. Li, A new application of aptamer: One-step purification and immobilization of enzyme from cell lysates for biocatalysis, Journal of biotechnology, 203(2015).

[28] T. Kavitha, I.-K. Kang, S.-Y. Park, Poly (acrylic acid)-grafted graphene oxide as an intracellular protein carrier, Langmuir, 30(2013) 402-9.

[29] Y. Liu, Y. Fang, J. Qian, Z. Liu, B. Yang, X. Wang, Bio-inspired polydopamine functionalization of carbon fiber for improving the interfacial adhesion of polypropylene composites, RSC Advances, 5(2015) 107652-61.

[30] L. Piao, Q. Liu, Y. Li, C. Wang, Adsorption of I-Phenylalanine on Single-Walled Carbon Nanotubes, The Journal of Physical Chemistry C, 112(2008) 2857-63.

[31] E. Mwafy, Multi walled carbon nanotube decorated cadmium oxide nanoparticles via pulsed laser ablation in liquid media, Optics \& Laser Technology, 111(2019) 249-54.

[32] W. Wei, D.F. Li, X.H. Pan, S.Q. Liu, Electrochemiluminescent detection of Mucin 1 protein and MCF-7 cancer cells based on the resonance energy transfer, Analyst, 137(2012) 2101-6. 
[33] T. Maxwell, T. Banu, E. Price, J. Tharkur, M.G.N. Campos, A. Gesquiere, et al., Non-cytotoxic 598 quantum dot-chitosan nanogel biosensing probe for potential cancer targeting agent, $599 \quad$ Nanomaterials, 5(2015) 2359-79.

600 [34] P. Nie, C. Min, H.-J. Song, X. Chen, Z. Zhang, K. Zhao, Preparation and Tribological Properties of 601 Polyimide/Carboxyl-Functionalized Multi-walled Carbon Nanotube Nanocomposite Films Under Seawater Lubrication, Tribology Letters, 58(2015).

[35] V.N. Boya, R. Lovett, S. Setua, V. Gandhi, P.K.B. Nagesh, S. Khan, et al., Probing mucin interaction behavior of magnetic nanoparticles, Journal of Colloid and Interface Science, 488(2017) 258-68.

[36] V.K. Thakur, J. Yan, M.-F. Lin, C. Zhi, D. Golberg, Y. Bando, et al., Novel polymer nanocomposites from bioinspired green aqueous functionalization of BNNTs, Polym Chem, 3(2012) 962-9.

[37] A.M. Mohammed, I.K. Al-Khateeb, A.J. Haider, R.A. Rahim, U. Hashim, Preparation of DNA biosensor application from fuel oil waste by functionalization and characterization of MWCNT, Sensing and Bio-Sensing Research, 16(2017) 1-5.

[38] S. Co, Functionalized multi-walled carbon nanotubes for enhanced photocurrent in dyesensitized solar cells, Journal of Nanostructure in Chemistry, 19(2013).

[39] L. Radev, M. Fernandes, I. Salvado, D. Kovacheva, Organic/Inorganic bioactive materials Part III: in vitro bioactivity of gelatin/silicocarnotite hybrids, Central European Journal of Chemistry, $7(2009)$ 721-30.

[40] M.H. Nawaz, A. Hayat, G. Catanante, U. Latif, J.L. Marty, Development of a portable and disposable NS1 based electrochemical immunosensor for early diagnosis of dengue virus, Analytica Chimica Acta, 1026(2018) 1-7.

[41] C. Ye, M.Q. Wang, Z.F. Gao, Y. Zhang, J.L. Lei, H.Q. Luo, et al., Ligating Dopamine as Signal Trigger onto the Substrate via Metal-Catalyst-Free Click Chemistry for "Signal-On" Photoelectrochemical Sensing of Ultralow MicroRNA Levels, Analytical Chemistry, 88(2016) 11444-9. [42] Y. Lin, Q. Zhou, D. Tang, Dopamine-Loaded Liposomes for in-Situ Amplified Photoelectrochemical Immunoassay of AFB1 to Enhance Photocurrent of Mn2+-Doped Zn3(OH)2V2O7 Nanobelts, Analytical Chemistry, 89(2017) 11803-10.

[43] M. Hasanzadeh, M. Feyziazar, E. Solhi, A. Mokhtarzadeh, J. Soleymani, N. Shadjou, et al., Ultrasensitive immunoassay of breast cancer type 1 susceptibility protein (BRCA1) using poly (dopamine-beta cyclodextrine-Cetyl trimethylammonium bromide) doped with silver nanoparticles: A new platform in early stage diagnosis of breast cancer and efficient management, Microchemical Journal, 145(2019) 778-83.

[44] Y. Fu, K. Zou, M. Liu, X. Zhang, C. Du, J. Chen, Highly Selective and Sensitive Photoelectrochemical Sensing Platform for VEGF165 Assay Based on the Switching of Photocurrent Polarity of CdS QDs by Porous Cu2O-CuO Flower, Analytical Chemistry, 92(2020) 1189-96.

[45] C.-C. Chang, N.-F. Chiu, D.S. Lin, Y. Chu-Su, Y.-H. Liang, C.-W. Lin, High-sensitivity detection of carbohydrate antigen 15-3 using a gold/zinc oxide thin film surface plasmon resonance-based biosensor, Analytical chemistry, 82(2010) 1207-12.

[46] S. Rauf, G.K. Mishra, J. Azhar, R.K. Mishra, K.Y. Goud, M.A.H. Nawaz, et al., Carboxylic group riched graphene oxide based disposable electrochemical immunosensor for cancer biomarker detection, Analytical Biochemistry, 545(2018) 13-9.

[47] I.A. Darwish, T.A. Wani, N.Y. Khalil, D.A. Blake, Novel automated flow-based immunosensor for real-time measurement of the breast cancer biomarker CA15-3 in serum, Talanta, 97(2012) 499-504. [48] W. Li, R. Yuan, Y. Chai, S. Chen, Reagentless amperometric cancer antigen 15-3 immunosensor based on enzyme-mediated direct electrochemistry, Biosensors and Bioelectronics, 25(2010) 254852.

[49] A.-E. Radi, X. Muñoz-Berbel, V. Lates, J.-L. Marty, Label-free impedimetric immunosensor for sensitive detection of ochratoxin A, Biosensors and Bioelectronics, 24(2009) 1888-92. 


\title{
Dopamine/mucin-1 functionalized electro-active carbon nanotubes as a probe for direct competitive electrochemical immunosensing of breast cancer biomarker
}

\author{
Sidra Rashid ${ }^{1}$, Mian Hasnain Nawaz ${ }^{1}$, Ihtesham ur Rehman ${ }^{2}$, Akhtar Hayat ${ }^{1}$, Jean \\ Loius Marty ${ }^{3 *}$. \\ 1. Interdisciplinary Research Centre in Biomedical Materials (IRCBM), COMSATS \\ University Islamabad, Lahore Campus, Pakistan. \\ 2. Bioengineering, Engineering Department, Lancaster University, Lancaster, UK \\ 3. Sensbiotech, 21rue de Nogarede, 66400 Ceret, France. \\ *Corresponding author: akhtarhayat@cuilahore.edu.pk; sensbiotech@gmail.com
}

\begin{abstract}
Mucin-1 (MUC-1) is associated with a broad range of human epithelia including gastric, lung and colorectal. In this work, a direct competitive electrochemical immunosensor based on gelatin modified transduction platform was designed. Dopamine (DA)/mucin-1 functionalized electro-active carbon nanotubes were employed as signal generating probes in the construction of electrochemical immunosensor for early stage diagnosis of breast cancer. The gelatin modified electrode served as a support to immobilize antibody (anti-MUC-1), while electrochemical response of functionalized electro-active carbon nano probes was used for quantitative measurement of MUC-1. Cyclic Voltammetry (CV) and Electrochemical Impedance Spectroscopy (EIS) were carried out to characterize the transduction surface at different fabrication steps. The developed immunosensor permitted the detection of MUC-1 in the linear range of $0.05-940 \mathrm{U} / \mathrm{mL}$, with a detection limit (LOD) of $0.01 \mathrm{U} / \mathrm{mL}$. The immunosensor showed recovery values in the range of $96-96.67 \%$ for human serum sample analysis, demonstrating its practical applicability.
\end{abstract}

Key words: MWCNTs, Mucin, Gelatin, Dopamine, Electrochemical Immunosensor, Direct immobilization, Competitive assay. 
32

33

34

35

36

\section{Introduction}

Breast cancer is one of the most common causes of women mortality. The mortality rate can be reduced to a significant level with the early stage diagnosis of breast cancer biomarkers [1]. However, the trace level of biomarkers in the serum of early cancer patients is one of the limiting factors towards diagnosis [2]. In this context, increasing demand for the detection of ultralow amount of cancer biomarkers has resulted in the exploration of different signal amplification strategies towards fabrication of ultrasensitive electrochemical immunoassays [3]. Several traditional techniques including radioimmunoassay, enzyme-linked immunosorbent assay (ELISA), electrophoretic immunoassay, fluorescence immunoassay, immune-polymerase chain reaction (PCR) and mass spectrometric immunoassay have been used for this purpose. However, they undergo operational limitations and hence, it is highly desirable to develop ultrasensitive, simple and easily automated device for early diagnosis of cancer biomarkers [4]. Electrochemical immunosensors with inherent advantages of cost effectiveness, higher sensitivity and lower power requirement have been applied for clinical diagnosis [5].

In such ultrasensitive immunosensors, nanomaterials can either be used directly as an electroactive label or as a substrate material to immobilize the electro-active labels [6]. Among the wide range of nanomaterials, multi-walled carbon nanotubes (MWCNTs) have been considered as a very promising material to enhance electron transfer rate on the transducer surface. Owing to their intrinsic electrical and electrochemical properties, MWCNTs are highly suitable for their integration into sensing strategies [7]. However, the presence of strong Van der Waals interactions among MWCNTs results their aggregation which limits their applications [8]. In this direction, the introduction of highly active functional groups via covalent modification of MWCNTs could enhance the electrochemical features of MWCNTs. For instance, the introduction of carboxylic groups on MWCNTs could covalently bond the amine residues of biological receptor elements [9]. Such biomolecule coated nanomaterials have been applied for the recognition of analytes. Consequently, electrostatically and covalently coupled carbon nanotubes not only stabilize the biomolecules but also offer distinct advantages including higher binding capacity, improved stability and reduced cost per assay [10, 11]. Currently, MWCNTs coated with both, biological recognition elements and electro-active labels have been investigated simultaneously, for molecular recognition and signal amplification [12]. 
DA is an important member of the catechol family, which is hydrophilic in nature and considered as an electron donor with variable redox properties [13]. DA and its derivatives have been reported to design signal amplification probes for construction of electrochemical biosensors [14]. Furthermore, the functional groups of DA including amine, imine, quinone and catechol enable DA to bind with a broad range of biomolecules [15]. In this regard, we have developed a DA coated MUC-1 conjugated MWCNTs nanoprobe. The MUC-1 was linked through amide bond formation with MWCNTs, while with DA using its amine and carboxylic groups respectively. This nanoprobe was subsequently integrated with carbon interface of working electrode to construct a direct competitive electrochemical immunosensor.

On the other hand, despite the advantages of nano-amplification technologies in electrochemical immunosensor, the unmodified electrodes are prone to major drawbacks of poor sensitivity, higher oxidation potential and fouling of the electrode response [16]. To overcome these problems, modification of the electrode surface with appropriate materials is of critical importance. Besides providing specific immobilization support for recognition elements, natural polymers have the ability to overcome the disadvantages of biological damages and toxicity imposed by non-biological transducing materials [17]. In this direction, it is highly desirable to fabricate a transducer surface with increased number of binding sites to improve the analytical merits of the biosensor. Amino acids modified transducer platforms provide a high surface area and abundant functional groups, which subsequently improve their stability and sensitivity. Gelatin is a linear polypeptide with large number of amine/carboxylic functional groups which provide a specific immobilization support for bioreceptors to design electrochemical biosensors [18]. The electro-oxidation of gelatin can render free amine groups on the transducer surface for interaction with carboxylic groups of Fc region of antibody [19]. Thus, it provides an efficient platform for the effective immobilization of the antibody [20]. Antibody immobilization on the electrode is considered to determine the surface charge of the transducer surface. This surface charge undergoes alteration upon immunoreaction with the given antigen [21]. Moreover, direct immobilization of biorecognition elements via covalent modification is known to improve the sensitivity of electrochemical immunosensors for various applications [22]. Direct assays involving antibody immobilization on modified electrode offer the advantages of sensitivity and stability over the indirect strategies. In addition, the immobilization of antibody on modified electrode can recognise even the low level of analyte for diagnostic purpose [23]. 
Keeping in view the above objectives, a direct electrochemical immunosensor based on DA coated MUC-1 conjugated functionalized multi walled carbon nanotubes (DA/MUC1/fMWCNTs) was fabricated for the competitive detection of MUC-1. MWCNTs were used to provide large surface area, while DA was employed to attain better sensitivity towards the target analyte. This fabrication approach resulted in a highly sensitive and selective transduction platform for the analysis of MUC-1 biomarker. The designed strategy was demonstrated for the analysis of breast cancer biomarker, however, it can be very easily extended to other biomarkers for diverse applications.

\section{Experimental Details}

\subsection{Materials}

Potassium ferrocyanide $\left(\mathrm{K}_{4}\left[\mathrm{Fe}(\mathrm{CN})_{6}\right]\right)$, Sulfuric acid $\left(\mathrm{H}_{2} \mathrm{SO}_{4}, 98 \%\right)$, potassium ferricyanide $\left(\mathrm{K}_{3}\left[\mathrm{Fe}(\mathrm{CN})_{6}\right]\right)$, bovine serum albumin (BSA), fetal bovine serum (FBS), human serum and Prestige Antibodies (NS1) were purchased from Sigma (Taufkirchen, Germany). Cancer antigen mucin $(25 \mathrm{kU})$ was purchased from Lee bio (Maryland Heights, MO, USA). Lysozyme was purchased from Carbosynth (Berkshire, UK), while N-(3dimethylaminopropyle)-N-ethyle-carbodiimide hydrochloride (EDC) and N-hydroxy succinimide (NHS) were from Alfa Aesar (Heysham, UK). MWCNTs (D $\times$ L 4-5 nm × 0.5$1.5 \mu \mathrm{m})$ were purchased from Sigma-Aldrich, France.

\subsection{Apparatus}

Different spectroscopic techniques were employed to characterize the nanoprobe and immunosensor fabrication steps. Fourier transform infrared (FTIR) measurements were performed by using a Thermo Nicolet $6700^{\mathrm{TM}}$ spectrometer (Waltham, MA, USA). Scanning electron microscopy (SEM) studies were performed by using a VEGA-3-TESCAN (Brno, Czech Republic) with variable pressure mode (LMU). Images were taken in different magnification ranges at an accelerated voltage of $20 \mathrm{kV}$. UV-Visible (UV-Vis) measurements were performed with a UV-spectrophotometer (UV-1800, USA) that was equipped with UV probe software to measure the absorption parameters. XRD spectra were obtained from a Rigaku D/Max 2500 XRD (Rigaku Corp Japan), equipped with graphitic mono-chromator $(40 \mathrm{kV}, 40 \mathrm{~mA})$. A nickel filtered $\mathrm{Cu}-\mathrm{K} \alpha$ radiation source $(\lambda=1.5418 \AA)$ was used during the sample analysis. To inspect the surface topography, atomic force microscopy (AFM) was performed at AFM PARK XE-7 Systems (Suwon Korea) in noncontact mode. 
For electrochemical measurements, AMEL 2553, potentiostat/galvanostat equipped with ZPulse software was used. A conventional three electrode system with $\mathrm{Ag} / \mathrm{AgCl}$ as reference electrode, a pencil graphite electrode as working electrode and platinum wire as counter electrode was employed. The pencil graphite electrodes (PGE, $0.5 \mathrm{~mm}$ lead diameter) were purchased from Staedtler Mars GmbH \&amp; Co. KG, Germany. An electrode length measuring $1 \mathrm{~cm}$ was immersed in a solution per measurement to maintain the uniform surface area for all the electrochemical experiments. EIS experiments were carried out using $\left[\mathrm{Fe}(\mathrm{CN})_{6}\right]^{4-/ 3-}$ as a redox probe under an applied potential of $0.1 \mathrm{~V}$ (vs. $\mathrm{Ag} / \mathrm{AgCl}$ reference electrode). The frequency range was between $100 \mathrm{kHz}-0.2 \mathrm{~Hz}$, with an AC amplitude and sampling rate of $10 \mathrm{mV}$ and 10 points respectively. The EIS spectra were plotted in the form of complex plane diagrams (Nyquist plots, -Zim vs. Zre) and fitted to a theoretical curve corresponding to the equivalent circuit with a frequency response analyzer software (FRA).

\subsection{Preparation of nanoprobe}

To obtain the carboxy functionalized MWCNTs, a homogenous solution of MWCNTs was prepared $(2 \mathrm{mg} / \mathrm{mL})$ in distilled $\mathrm{H}_{2} \mathrm{O}$ under ultrasonication for 2 hours. Subsequently, chloroacetic acid $(1 \mathrm{~g} / \mathrm{mL})$ and $\mathrm{NaOH}(1.5 \mathrm{~g} / \mathrm{mL})$ were added to the reaction suspension. After sonication, supernatant was removed and remaining solution was allowed to dry. Then, fMWCNTs were treated with $100 \mathrm{mM}$ EDC-NHS solution containing MUC-1 protein for 45 min. For MUC-1 conjugation, $200 \mu \mathrm{L}$ of MUC-1 protein (1/100 dilution from stock solution) was mixed with the solution of NHS $(25 \mathrm{mM})$ and EDC $(100 \mathrm{mM})$ in the Phosphate Buffer Saline (PBS, $\mathrm{pH}$ - 7.4) for $45 \mathrm{~min}$. Subsequently, the supernatant was removed via centrifuge at $12000 \mathrm{rpm}$ to obtain the MUC-1 conjugated fMWCNTs. MWCNTs provided a large surface area for the attachment of MUC-1 protein to make a stable and promising immunosensing platform. Afterwards, DA $(1 \mathrm{mg} / \mathrm{mL})$ was added in the reaction mixture under vigorous stirring for $20 \mathrm{~min}$. The mixture was allowed to settle down. Excessive water was removed and left over was directly used for immunosensor fabrication.

\subsection{Fabrication of competitive electrochemical immunosensor}

Prior to gelatin grafting, the PGE was electrochemically cleaned in $0.5 \mathrm{M} \mathrm{H}_{2} \mathrm{SO}_{4}$ to reduce/oxidize impurities by successive cyclic voltammetric scans within the potential range from -1.5 to $1.5 \mathrm{~V}$. For electro oxidation of gelatin, the solution of gelatin $(2.5 \mathrm{mg} / \mathrm{mL})$ was prepared in acetate buffer $(\mathrm{pH}=5)$ at room temperature. Two consecutive cyclic voltammetric scans were run at a scan rate of $0.5 \mathrm{~V} / \mathrm{s}$ in the potential range from -1.2 to $0.4 \mathrm{~V}$ for the electro oxidation of gelatin on PGE surface. The modified electrode 
was incubated in $25 \mu \mathrm{L}$ of MUC-1 antibody solution $(0.25 \mathrm{U} / \mathrm{mL})$. The crosslinkers (EDC and NHS) were used to activate the carboxylic groups of gelatin on the electrode surface. The Electrode was then washed with PBS solution to remove the excess of unbound antibody. To block the residual carboxylic sites, diethanolamine was incubated on the electrode surface for a time period of $45 \mathrm{~min}$. For MUC-1 detection, $25 \mu \mathrm{L}$ of nanoprobe was incubated on the modified electrode surface for $45 \mathrm{~min}$. For the selectivity experiments of the fabricated immunosensor, various interfering moieties including FBS, BSA and NS1 were incubated on the sensor surface following a procedure similar to the one described for MUC-1 analysis.

\subsection{Quantitative detection of MUC-1}

Based on the principle of competitive-assay, the fabricated immunosensor was incubated with different concentrations of free MUC-1 for 15 min and subsequently washed with the PBS buffer. The peak current was recorded using the electrochemical workstation. The difference in the corresponding peak before and after the competition step was used for the quantitative analysis of MUC-1.

\subsection{Real Sample Analysis}

To validate the potential application of proposed immunosensor in clinical analysis, MUC-1 spiked human serum samples were analysed. Human serum was diluted (50 times) with PBS buffer to achieve the desired analyte concentration. The samples were spiked with three different concentrations of the analyte $(0.1,14.8$ and $473.6 \mathrm{U} / \mathrm{mL})$.

\section{Results and discussion}

\subsection{Detection mechanism of electrochemical immunosensor}

The mechanism of proposed electrochemical immunosensor based on DA assisted signal amplification strategy was presented in scheme 1 .

The detection strategy consists of three main steps: preparation of nanoprobe, modification of electrode surface and competitive recognition of free MUC-1. fMWCNTs provided - $\mathrm{COOH}$ groups for the attachment of MUC 1 protein, while DA was used to amplify the electrochemical signal due to its electron donating capability. The DA/MUC-1/fMWCNTs nanoprobe was synthesised by covalent binding of MUC-1 protein with DA. A robust way to create bio-functionalized surface is to immobilize the biological macromolecules such as antibodies or antigens at the modified electrode surface by means of covalent binding. This requires the presence of two mutually reactive chemical groups on the protein and on the 
substrate surface. The commonly employed literature methods exploit the reactivity of endogenous functional groups (such as amines and carboxylic acid groups) present in the side chains of the amino acids. In such strategies, the naturally occurring functional groups are used to covalently couple with the complementary functional groups present on the substrate surface. The carboxylic acid functional groups of these amino acids can react with amines using the coupling chemistry. This coupling reaction is usually activated by EDC/NHS agents which results in a rapid formation of a peptide bond. In general, the presence of excessive amount of amino acids can theoretically result in a random immobilization. However, immobilization methods based on covalent binding chemistry can provide surface coatings with a unique orientation of the antibody (Abs)-proteins. This covalent immobilization, in principle, provides the best entry point for Abs molecules to the protein (gelatin) modified surface with a specific orientation. This intermediated protein (gelatin) on electrode surface actually displays two and five binding domains specific to the Fc-portion of Abs that renders tail-on orientation (Fc attached to the surface) [24]. Um et al. introduced tail-on orientation of the Abs by the electrochemical immobilizing of a protein onto the electrode surface [25]. The electrostatic interactions between various functional groups such as amino groups on the modified (with gelatin in this case) surface and the oxygen containing groups of the $\mathrm{Ab}$ present in the $\mathrm{Fc}$ region also favour tail-on orientations of Abs due to steric hindrance imposed by side arms of the Abs. Abs possess only one binding site. Therefore, Abs should display free antigen-binding regions after immobilization to achieve the highest analyte binding. Thus, this tail-on orientation can improve biosensor performance with improvement factors as high as 200 being reported upon organized orientation [26]. Moreover, EDC/NHS activation approach possesses many merits including high conversion efficiency, mild reaction conditions, highly oriented biocompatibility with target molecules, and much cleaner products as compared to other crosslinking reagents. Therefore, the modified electrode in the strategy employed in this study with improved electro-active area supplied a non-random immobilized surface for MUC-1 antibody. The antibody was well oriented in this arrangement because of EDC assisted $-\mathrm{HN}-\mathrm{COOH}$ bond formation with gelatin-surface. In addition, the maximum numbers of MUC-1 antibody active sites were prone to epitopes attachment. 


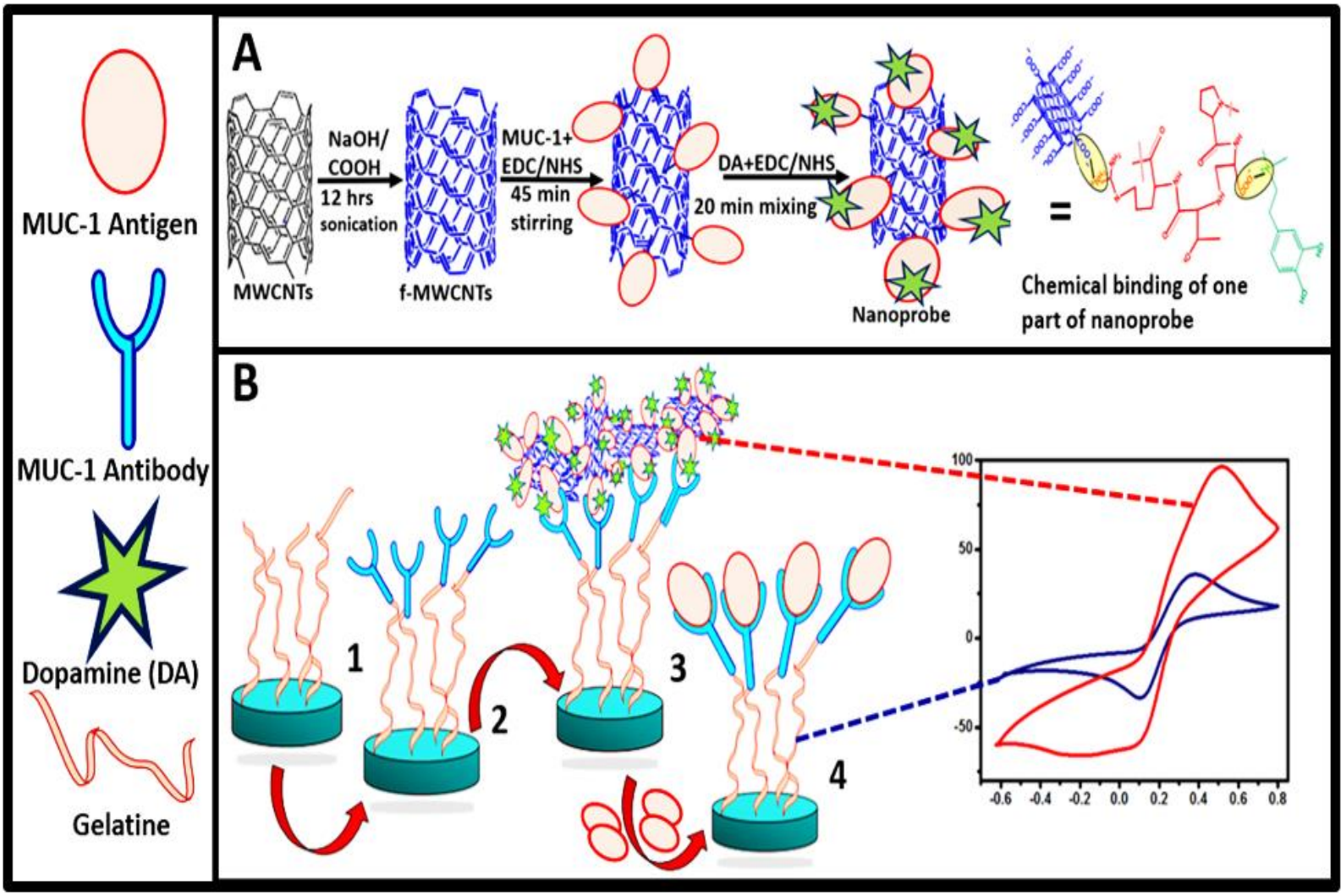

Scheme. 1. Schematic illustration of (A) different steps involved in the fabrication of nanoprobe, (B) Modification of working electrode and principle of direct competitive electrochemical immunosensor for breast cancer detection. (1) Electrooxidative grafting of gelatin on pencil electrode, (2) EDC/NHS attested binding of MUC-1 antibody, (3) Attachment of developed nanoprobe with modified electrode resulting in higher current signal, (4) Free MUC-1 replaced nanoprobe and resulting signal decreased in competitive assay.

The immunosensor was characterized both in ferri/ferro cyanide solution and PBS buffer.

Afterwards, when the immunosensor was used to recognize free MUC-1, a competitive process was carried out in PBS buffer. The proposed strategy is based on the direct competition between labelled and un-labelled antigen. The direct competition approach is well established detection mechanism in the literature. Both labelled and un-labelled antigens have equal binding tendencies, while the detection mechanism relies on the competition between both types of antigens. In the absence of free antigen, maximum signal intensity was observed while the presence of free antigen competed with the labelled one to bind with the immobilized antibody, thus decreasing the output signal. The decrease in response was proportional to the concentration of free analyte (antigen) and was employed for quantitative analysis of MUC-1. Since an electron donor (DA) was attached to the nanoprobe, a dramatic difference in current signal was observed in the absence and presence of free analyte. The immunosensor permitted to detect low level of MUC-1 in human serum samples and thus can be used for early diagnosis of breast cancer. 


\subsection{Characterization}

\section{$244 \quad$ 3.2.1 FTIR, UV-Vis, SEM, XRD and AFM analysis of nanoprobe}

245 FTIR spectra were used to evaluate and monitor the functional group changes during modification process of MWCNTs (Fig. 1A). No significant spectral bands appeared in case of MWCNTs, while a spectral peak at $1490 \mathrm{~cm}^{-1}$ was observed for C-H bending (a). However, in case of COOH-MWCNTs, several significant peaks appeared (b). Spectral peaks at $1202 \mathrm{~cm}^{-1}$ and 1490 to $1650 \mathrm{~cm}^{-1}$ were respectively assigned to $\mathrm{C}-\mathrm{O}-\mathrm{C}$ and $\mathrm{C}=\mathrm{C}$ bending modes. Spectral bands at 2850 to $2950 \mathrm{~cm}^{-1}$ represent C-H stretching vibrations. Another small spectral peak appeared at $3460 \mathrm{~cm}^{-1}$ for $\mathrm{OH}$-stretching of carboxylic group. Similarly, the spectral band at 2200 to $2300 \mathrm{~cm}^{-1}$ was assigned to $\mathrm{CO}_{2}$. However, upon incubation of MUC-1 protein (c), $\mathrm{C}=\mathrm{O}$ peak shifted to $1643 \mathrm{~cm}^{-1}$ and became broader due to amidecarbonyl stretching mode [27]. Small peaks at 1180, 1480 and $3430 \mathrm{~cm}^{-1}$ were assigned to aliphatic $\mathrm{C}-\mathrm{N}$ stretching, $\mathrm{N}-\mathrm{H}$ rocking and $\mathrm{N}-\mathrm{H}$ stretching vibrations, respectively [28]. A single absorption band appeared at $1636 \mathrm{~cm}^{-1}$, which was attributed to aromatic $(\mathrm{C}=\mathrm{C})$ of the
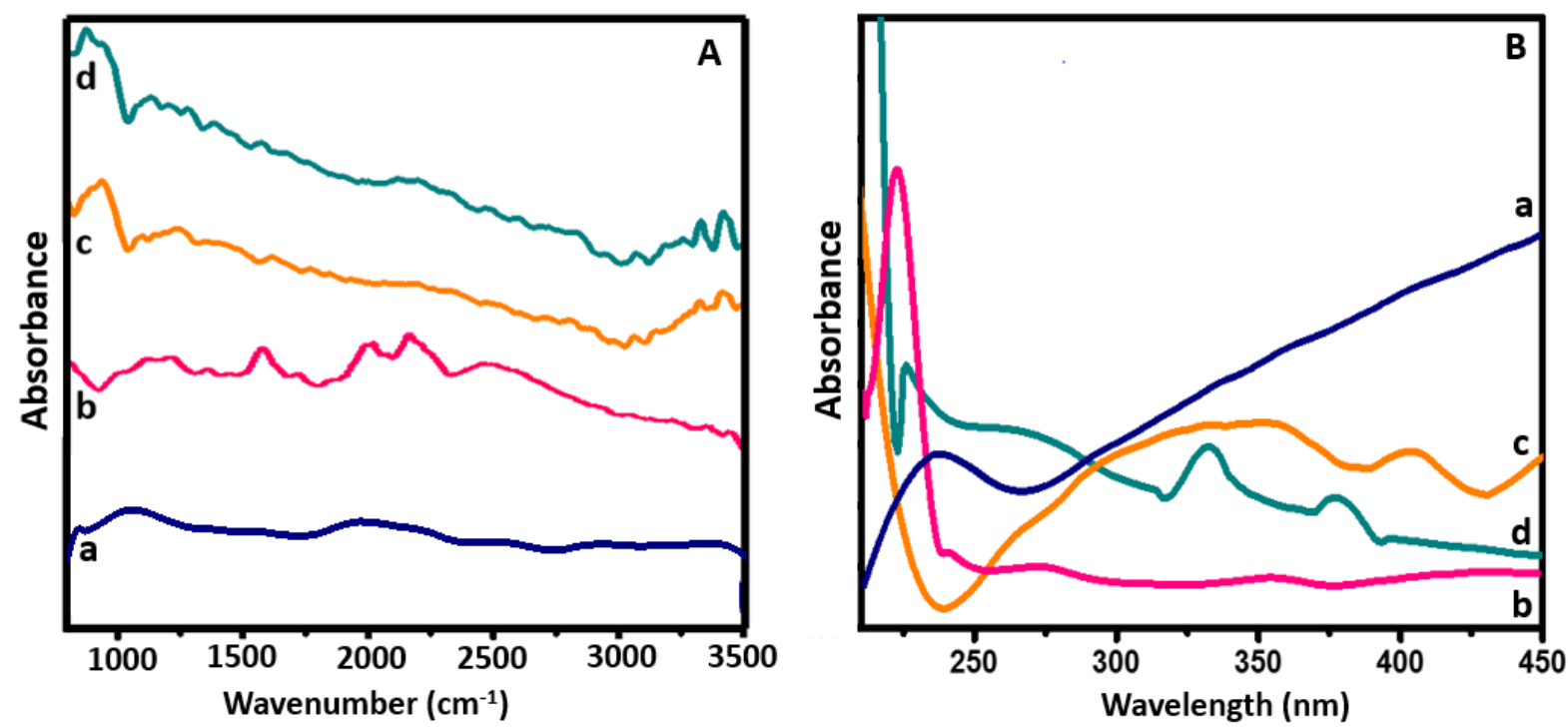

Fig. 1. (A) FTIR analysis and (B) UV-Vis spectra of a; MWCNTs, b) fMWCNTs, c) fMWCNTs/MUC-1 protein, d) fMWCNTs/MUC-1 protein/ DA.

Fig. 1.B shows the UV-Vis spectra of each modification step of MWCNTs during fabrication of electrochemical immunosensor. A characteristic peak of MWCNTs near $250 \mathrm{~nm}$ can be seen in Fig. 1B, a. The peak is in good agreement with the literature reporting characteristics of MWCNTs [30]. After acidic treatment (Fig. 1B, b), the transition absorption peaks near $250 \mathrm{~nm}$ became stronger with a red shift due to the electronic transition from $\mathrm{n} \rightarrow \pi^{*}$ of a nonbonding pair of electrons from carboxylic groups. It indicates that the functionalization 
process was efficient for MWCNTs to provide fMWCNTs. This red shift in the characteristic peak of MWCNTs corresponds to the presence of excessive carboxylic groups on the surface of fMWCNTs [31]. A characteristic peak at $260 \mathrm{~nm}$ was observed for MUC-1 as shown in Fig. 1B, c [32]. Finally, nanoprobe retained the characteristic absorption peaks of both MUC1 protein and DA at $368 \mathrm{~nm}$ [33], indicating the successful labelling of DA with nanoprobe 272 (Fig. 1B, d).

273 The functionalization process was based on the attachment of organic moieties on the material surface. Therefore, a change in surface morphology via SEM and AFM could be used as an indicator to show the variation in surface nature upon different modification steps.

276 The SEM images at different stages of nanoprobe fabrication are displayed in Fig. 2. It can be observed from Fig. 2 that the MWCNTs have different surface morphology as compared to those of functionalized MWCNTs (fMWCNTs), fMWCNTs/MUC-1 protein and fMWCNTs/MUC-1/DA). It can also be observed from the micrographs that the surfaceroughness of MWCNTs increased after functionalization with COOH. Similarly, fMWCNTs became closely packed upon the addition of MUC-1 protein, making the surface appearance of MWCNTs as covered with cloudy clusters. After interaction of DA (Fig. 2D), the modified MWCNTs were found to be disaggregated.

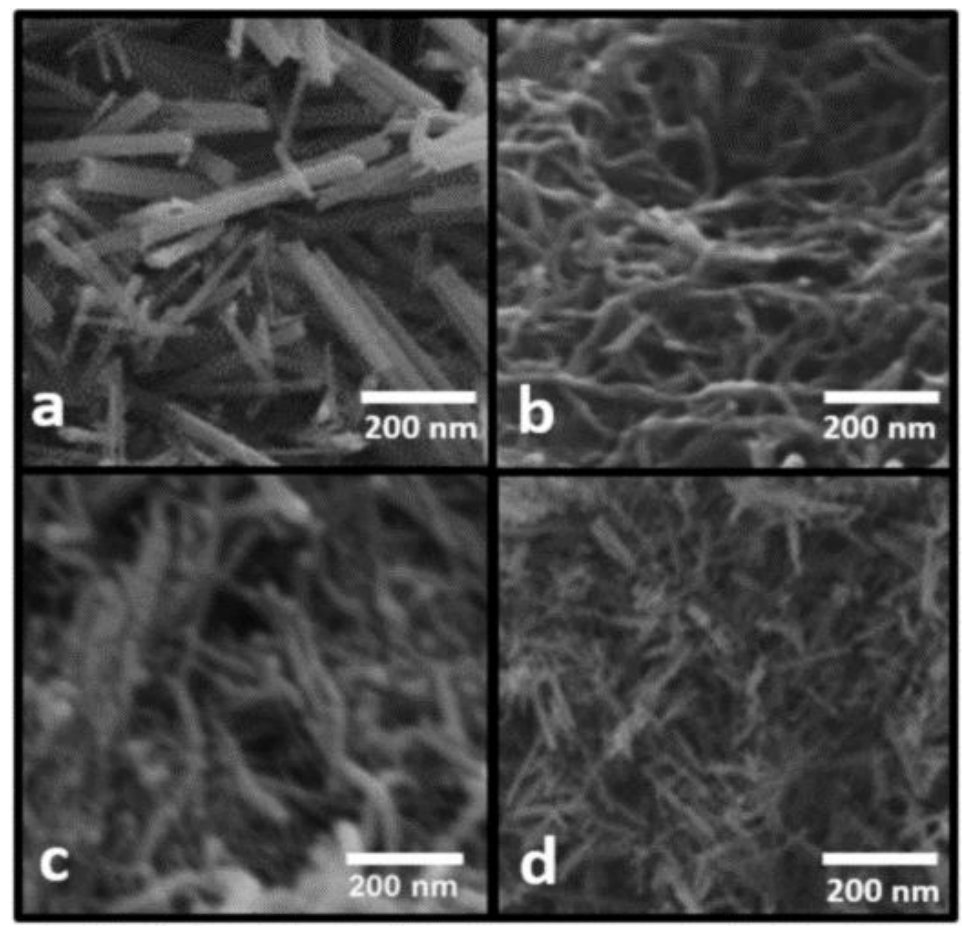

Fig. 2. SEM analysis of a; MWCNTs, b) fMWCNTs, c) fMWCNTs/MUC1 protein, d) fMWCNTs/MUC1 protein / DA. 
The XRD patterns for each fabrication step of nanoprobe were displayed in Fig. 3A. Typical peaks (002 and 100) of MWCNTs were obtained at $2 \Theta=26.68^{\circ}$ and $48^{\circ}$ respectively, which were in accordance with the reported literature. The intensity of 002 peak for fMWCNTs was increased as compared to pristine MWCNTs [34]. However, a decrease in the peak intensities was observed after the attachment of EDC/NHS treated MUC-1, with the appearance of additional peaks at $28.5^{\circ}$ and $46.7^{\circ}$, confirming the presence of MUC-1 on the surface of fMWCNTs [35]. XRD pattern of fMWCNTs/MUC-1 protein/DA, as shown in Fig. 3A, d depicted only one reduced peak of MWCNTs at $26^{\circ}$, while the other peaks were depressed due to the presence of DA [36].
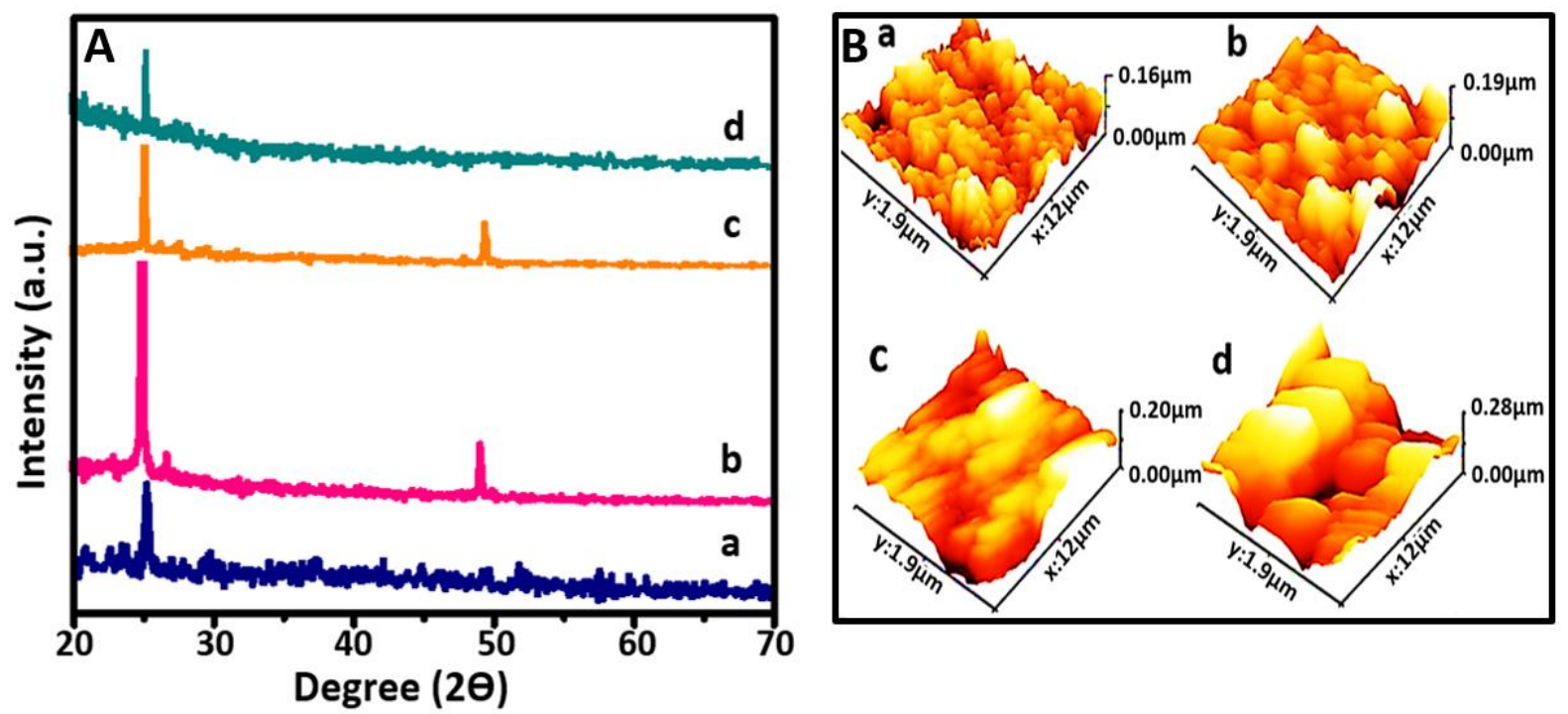

Fig. 3. (A) XRD analysis and (B) AFM topographs of step wise preparation of MUC-1 immunoprobe. a) MWCNTs, b) fMWCNTs, c) fMWCNTs/MUC-1 protein, d) fMWCNTs/MUC-1 protein/DA.

AFM was used for the investigation of surface morphology of nanoprobe. The topography images are given in Fig. 3B. Image (a) indicates the rough surface features of MWCNTs [37]. After functionalization process, the surface roughness was reduced with increased cluster formation. This decrease was attributed to the smoothing effect induced by f-MWCNTs [38]. Similarly, the immobilization of antibody increased the profile height with a changed surface morphology, thus indicating the attachment of large size molecules (antibody) on the surface of fMWCNTs (c). Finally, the DA attachment altered the height and surface of the topographical profile as shown in Fig. 3B, d.

\subsubsection{Characterization of modified electrode}

In Fig. 4A, the XRD images of modified electrode were presented. Peaks close to $28.1^{\circ}$ and $32.6^{\circ}$ were the characteristic peaks for carbon surface. After the immobilization of gelatin, the peaks were diminished. While the appearance of peak at $26.4^{\circ}$ proved the successful 
electro-oxidation of gelatin on the electrode surface. This XRD pattern reveals the amorphous structure of gelatin [39]. However, these peaks were decreased on the attachment of antibody, which occupied the carboxylic groups for amide bond formation. The addition of analyte further diminished the majority of the peaks, indicating the effective attachment of analyte on the transducer surface.
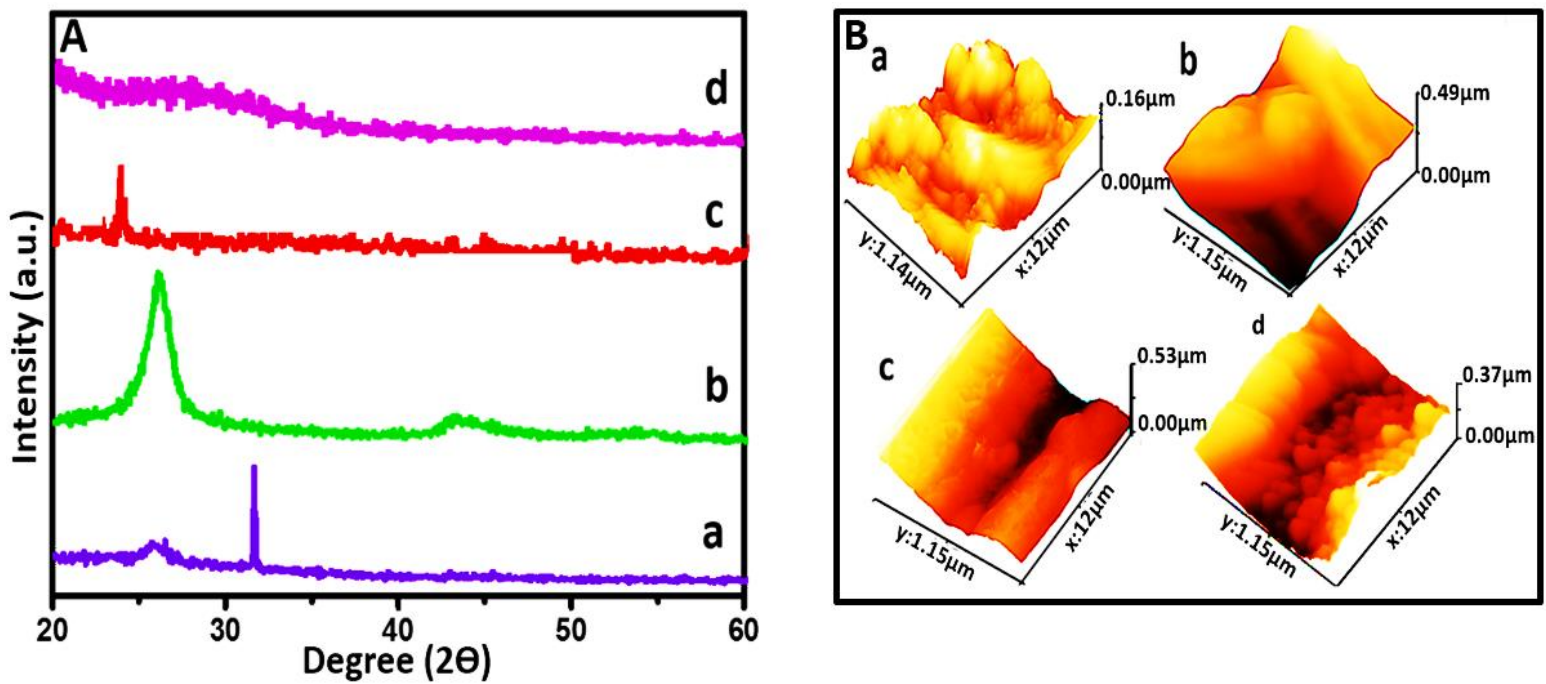

Fig. 4. (A) XRD and (B) AFM images of a) Bare electrode, b) Gelatin modified electrode, c) Gelatin modified electrode with MUC-1 antibody, d) Gelatin modified electrode with MUC-1 antibody + free MUC-1.

The stepwise investigation of electrode fabrication protocol was also performed using AFM topographic profiling. Fig. 4B, a represents the surface of bare electrode with a profile height of 0.00-0.16 $\mu \mathrm{m}$ and irregular trough and crust contrast. Gelatin grafting resulted in uniform topology with increased profile height, suggesting the effective immobilization of proteinic clusters, as shown in Fig. 4B, b. An improved smooth surface with increased profile height (Fig. 4B, c) was observed after the attachment of antibody, indicating the presence of bulky molecules on the modified electrode. Moreover, the specific attachment of analyte (MUC-1) resulted in the reversal of profile height and morphology, as illustrated in Fig. 4B, d. Such reversal of morphological features could be attributed to the breakage of clusters of antibody molecules [40].

\subsection{Electrochemical Characterization}

$\mathrm{CV}$ and EIS were performed for the characterization of each working step and different stages, involved in the fabrication of proposed immunosensor. CV and EIS are considered powerful tools to study the electrochemical characteristics of transducing surfaces. All electrochemical characterizations were carried out in the presence of $\left[\mathrm{Fe}(\mathrm{CN})_{6}\right]^{4-/ 3-}(1 \mathrm{mM})$ as an electro-active redox probe. This probe permits the recognition of high current response against the behaviour of electrochemically inert solution. In CV, differences in the peak 
currents (PC) and peak to peak separations were monitored to characterize each fabrication step of the electrochemical immunosensor. Similarly, EIS is also considered as a very effective electrochemical technique for surface modification characterization. The Nyquist plot with a semicircle portion at higher frequencies corresponds to the electron transfer resistance. Impedance spectra (Nyquist plots) for each surface modification step were recorded using the Randles equivalent circuit. The circuit consisted of ohmic electrolyte resistance $\left(R_{\mathrm{S}}\right)$, the electron-transfer resistance $\left(\mathrm{R}_{\mathrm{et}}\right)$, the Warburg impedance element $\left(\mathrm{Z}_{\mathrm{W}}\right)$ resulting from the diffusion of ions from the bulk of the electrolyte to the interface, and the constant phase element. The $\mathrm{R}_{\mathrm{et}}$ depends on the insulating feature at the electrode/electrolyte interface and represents facial properties of the surface. $R_{\text {et }}$ is the useful parameter to evaluate interfacial properties. Therefore, $\mathrm{R}_{\mathrm{et}}$ was considered to monitor the changes on the electrode interface at each fabrication step for the designed immunosensor.

\subsubsection{Characterization of nanoprobe assembly}
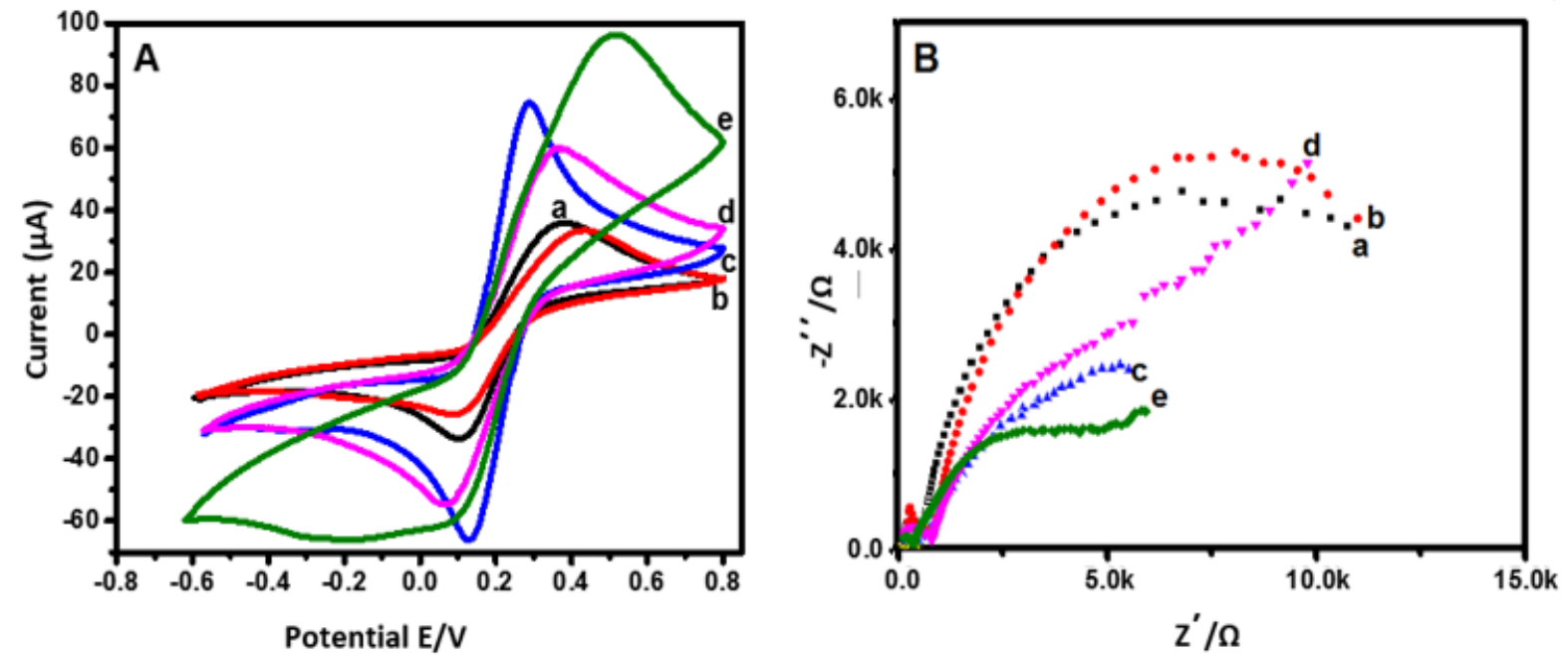

Fig. 5. (A) Cyclic voltammograms and (B) Electrochemical Impedance spectra of different steps involved in nanoprobe preparation; a. Bare PGE, b. MWCNTs, c. fMCNTs/EDC-activated, d. fMCNTs/EDCactivated/MUC-1 protein, e. fMCNTs/EDC-activated/ MUC-1 protein/DA.

Cyclic voltammograms for all fabrication steps involved in the formation of nanoprobe are shown in Fig. 5A. The representative anodic and cathodic peaks were observed for (a) Bare PGE, (b) MWCNTs, (c) fMWCNTs/EDC-activated, (d) fMWCNTs/EDC-activated/MUC-1 protein, and (e) fMWCNTs/EDC-activated/ MUC-1 protein/DA. A characteristic redox peak of bare PGE with the anodic and cathodic peak current was observed. The presence of MWCNTs resulted in a decrease in the current with increased electron transfer resistance $\left(\mathrm{R}_{\mathrm{et}}\right)$. After the formation of fMWCNTs/EDC-activated PGE, the $\mathrm{R}_{\mathrm{et}}$ between electrode surface and activated fMWCNTs was reduced due to the succinimide moiety introduced by 
EDC-activation. After the immobilization of MUC-1 protein, the negatively charged phosphate groups resulted in the higher $\mathrm{R}_{\mathrm{et}}$ value. However, upon addition of DA, an increased CV-response was observed. Basically, well assembled DA on the nanoprobe facilitated the flow of electrons [41]. The trend of the impedimetric response of all the fabrication steps was found to be the analogue of their CV response as can be evidenced in the Fig. 5A and 5B.

368

369

370

371

372

\subsubsection{Characterization of transducer surface fabrication}

Electro-oxidation of gelatin was performed in acetate buffer $(\mathrm{pH}=5)$. A representative first scan of oxidation process is shown in Fig. 6A. After deposition of gelatin, the modification steps were characterized in the presence of $1 \mathrm{mM}$ redox couple $\left[\mathrm{Fe}(\mathrm{CN})_{6}\right]^{4-/ 3-}$. The $\mathrm{CV}$ current of the bare electrode enhanced (approximately 2-folds) after electrochemical oxidation of gelatin on PGE surface while peak shifted to the higher potential, as shown in Fig. 6B, b.
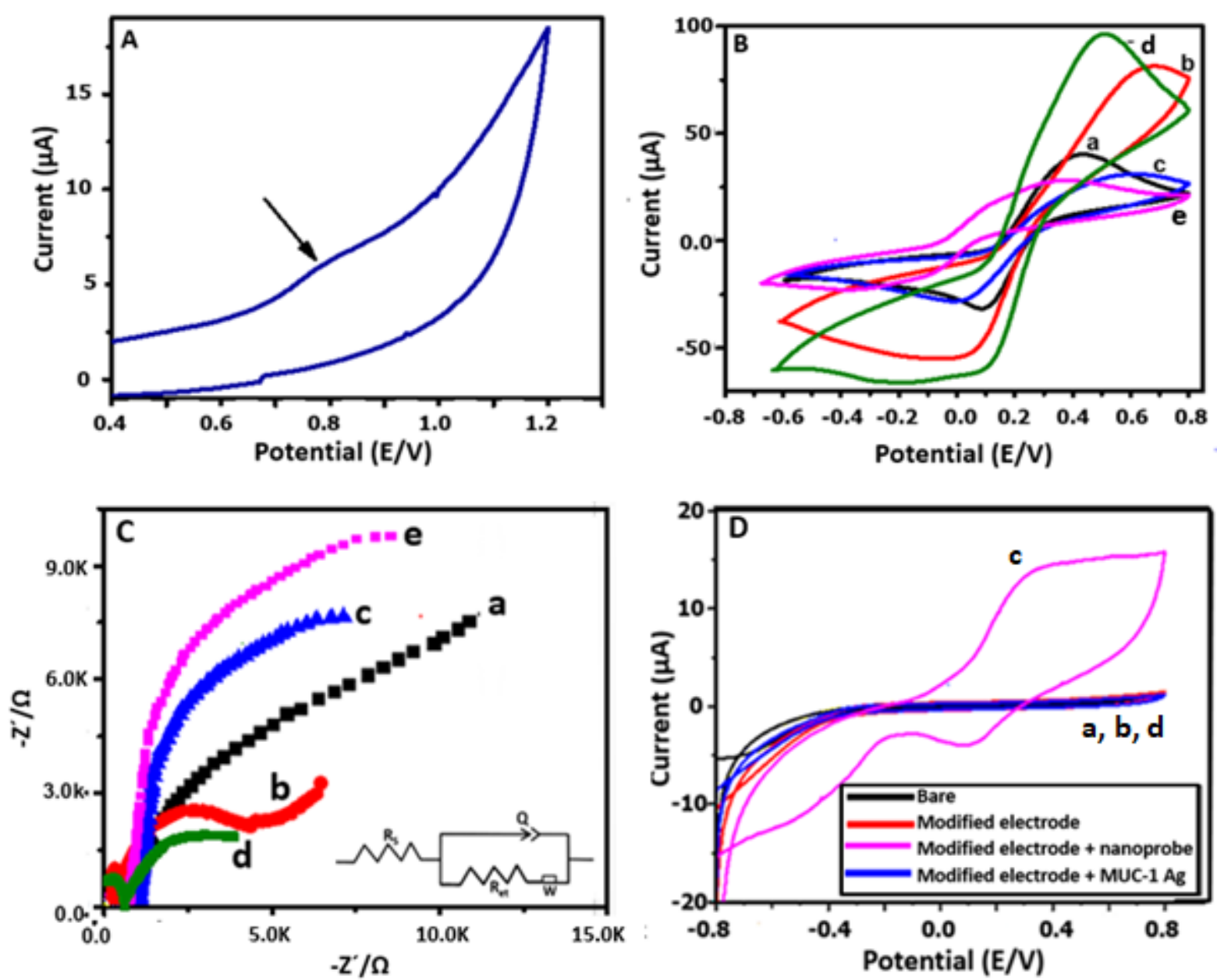

Fig. 6. (A) Characteristic CV curve for electro-oxidation of gelatin (first cycle) on PGE-surface $(2.5 \mathrm{mg} / \mathrm{mL}$ in involved in the fabrication of immunosensor; a. Bare, b. Bare/gelatin, c. Bare/gelatin/antibody, d. 
Bare/gelatin/antibody/nanoprobe, e. Bare/gelatin/antibody/nanoprobe/free MUC-1. (D) Cyclic Voltammograms of immunosensor in PBS to demonstrate the working mechanism; a. Bare, b. gelatin, c. gelatin/nanoprobe, d. gelatin/nanoprobe/MUC-1 Ag.

With gelatin grafting, a good peak to peak separation was observed. These electrochemical changes suggested an increased electron transfer rate between modified electrode surface and the electrolyte solution. The EDC/NHS treated MUC-1 antibody immobilization resulted in a reduction of electron transfer, showing a further peak shifting towards higher potential as represented in Fig. 6B, c. The immobilization of nanoprobe resulted in a very prominent redox peak (Fig. 6B, d). However, upon incubation of analyte (MUC-1), a clear decrease in peak current was observed (Fig. 6B, e). This enhanced signal in case of nanoprobe was mainly contributed by DA, which is an efficient electron-donor. It is note-worthy that the electron donor signal probes can be attached precisely to the target analyte for signal amplification [41]. The maximum surface of fMWCNTs was covered by MUC-1, hindering the attachment of DA molecules on the surface of fMWCNTs. Moreover, the DA was used as an electron donor and the intensity of current signal was dependent on the amount of attached DA. DA has been employed as a probe to donate electrons for signal amplification in the construction of the electrochemical biosensors [42]. It can also be observed from the Fig. 6 that the combination of DA and MUC-1 altered the nature of peak current, which could be attributed to the high electrical conductivity of DA [43]. When MUC-1 antigen competed with the MUC-1 nanoprobe containing DA, the peak current was decreased. Additionally, the antigens acted as an insulator and subsequently reduced the electron transfer rate [44]. This could be attributed to the antibody-antigen complex on the surface of the modified electrode $[20]$.

Similarly, Fig. 6D represents the electrochemical response of PGE at different modification steps in PBS. A characteristic redox peak of DA was observed in the presence of DA labelled MUC-1 (Fig. 6D, c), while the given characteristic peak was significantly decreased upon competition between free and DA labelled MUC-1, as shown in the Fig. 6D, d. This further demonstrates the working mechanism of fabricated immunosensor. Similarly, bare and gelatin modified electrodes did not show any response.

\subsection{Competition assay for MUC-1 protein}

Prior to perform competition assay, different experimental conditions were optimized. The detail of the experimental optimization is provided in the supporting information (SI). To validate the immobilization method, direct competitive immunoassays were performed for MUC-1 analysis using optimized experimental parameters. The assays were relied on the 
competition between the free MUC-1 and labelled MUC-1 nanoprobe. When the system was tested without free MUC-1 by CV, a current signal of $98.9 \mu \mathrm{A}$ was obtained as shown in Fig. 6B.This current was high enough to carry out the competition step and measure the lower current intensities (Fig. 7A). The proposed strategy was based on the direct competition between labelled and un-labelled antigen. The direct competition approach is well established detection mechanism in the literature. Both labelled and un-labelled antigens have equal binding tendencies, while the detection mechanism relies on the competition between both types of antigens. In the absence of free antigen, a maximum signal was observed while the presence of free antigen competed with the labelled one to bind with the immobilized antibody, thus decreasing the output signal. The decrease in response was proportional to the concentration of free analyte (antigen), hence, utilized for its quantitative analysis. For the higher concentrations (473.6 and $940 \mathrm{U} / \mathrm{mL}$ ), the change in current response was difficult to be observed due to saturation point. The calibration curve obtained with electrochemical immunosensor is shown in Fig. 7B. Due to experimental error (5\%), the LOD was defined as the MUC-1 concentration, which corresponds to the $85 \%$ of MUC-1 binding depending on the maximum standard deviation value. The calibration curve (Fig. 7B) was fitted by sigmoidal logistic four parameter-equation $\mathrm{y}=\mathrm{a}_{2}+\left[\mathrm{a}_{1}-\mathrm{a}_{2} / 1+\left(\mathrm{x} / \mathrm{x}_{0}\right)^{p}\right]$ using Origin Pro- 8 SR0 software, in which $\mathrm{a}_{2}$ and $\mathrm{a}_{1}$ are the maximum and minimum values respectively, and $\mathrm{x}^{0}$ and $p$ are the $\mathrm{x}$ value at the inflection point and the slope of inflection point accordingly. With the help of equation, percentage binding was evaluated depending upon the maximum standard deviation value. The lower percentage binding (less than $100 \%$ ) could be linked with the high number of the washing steps that might cause leaching of excessive antibodies out of the electrode surface. The correlation coefficient R, LOD and IC50 values were found 436 to be $0.95,0.01 \mathrm{U} / \mathrm{mL}$ and $7.4 \mathrm{U} / \mathrm{mL}$ respectively, from regression equation.
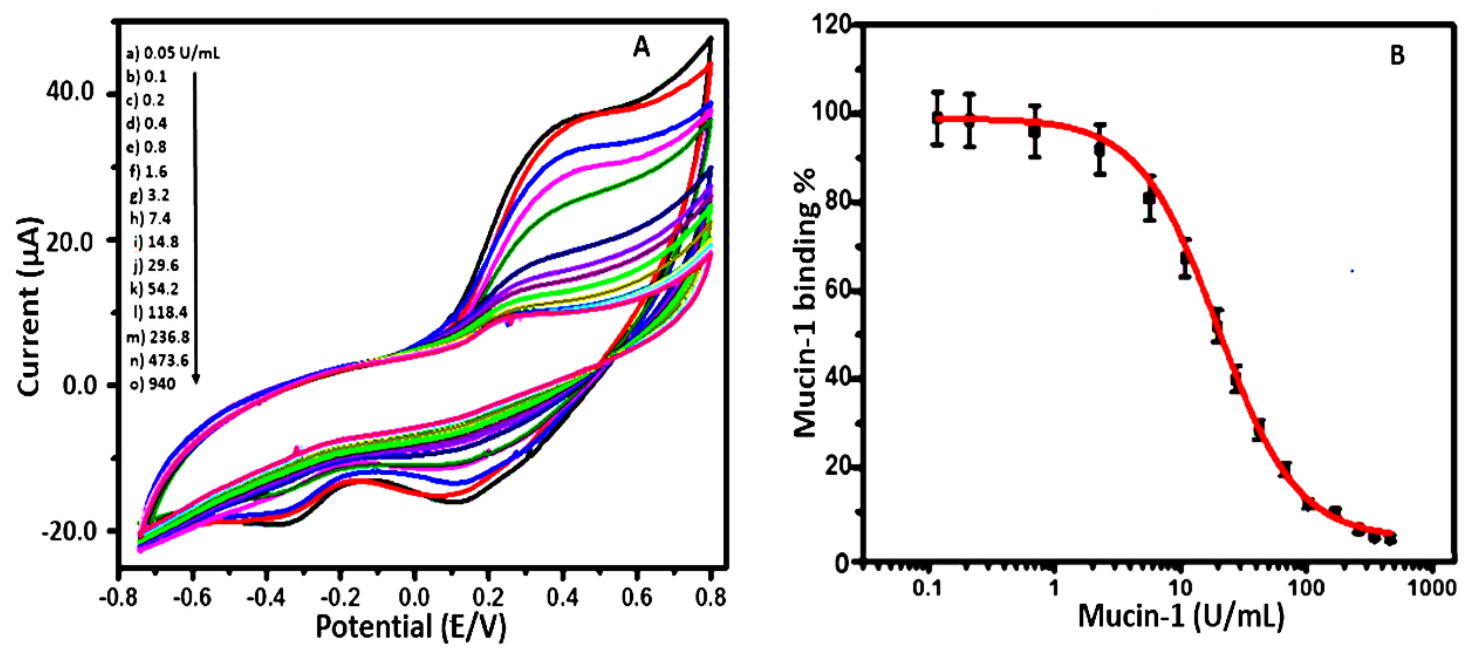
Fig. 7. Variation of CV with increasing concentration of free MUC-1 for competition assay (A) and standard curve for proposed assay (B). Experimental conditions: Gelatin concentration $=0.1 \mathrm{M}$, antibody concentration= $0.25 \mathrm{U} / \mathrm{mL}$, antibody incubation time $=30 \mathrm{~min}$, nanoprobe concentration $=25 \mu \mathrm{L}$, nanoprobe incubation time $=$ $15 \mathrm{~min}$, DA concentration $=0.1 \mathrm{M}, \mathrm{pH}$ of buffer $=7.2$.

Table 1 presents a comparison between the given electrochemical immunosensor and the existing literature reports for the detection of cancer biomarker.

Table 1. A comparison of present work with the published literature reports for the detection of MUC-1.

\begin{tabular}{|c|c|c|c|c|c|}
\hline No. & $\begin{array}{l}\text { Material } \\
\text { Used }\end{array}$ & $\begin{array}{l}\text { Detection } \\
\text { Method }\end{array}$ & $\begin{array}{l}\text { LOD } \\
(\mathrm{U} / \mathrm{m} \\
\mathrm{L})\end{array}$ & $\begin{array}{l}\text { Linear } \\
\text { Range } \\
(\%)\end{array}$ & Ref. \\
\hline 1 & $\begin{array}{l}\mathrm{Au} / \mathrm{ZnO} \text { thin film } \\
\text { surface }\end{array}$ & $\begin{array}{l}\text { Plasmon Resonance } \\
\text { Based }\end{array}$ & 0.025 & $1-40$ & [45] \\
\hline 2 & $\begin{array}{l}\mathrm{COOH} \\
\text { graphene oxide }\end{array}$ & $\begin{array}{l}\text { Disposable } \\
\text { electrochemical } \\
\text { immunosensor }\end{array}$ & 0.04 & $0.1-2$ & [46] \\
\hline 3 & $\begin{array}{l}\text { Coated } \\
\text { Polymethylmethacr } \\
\text { ylate }\end{array}$ & $\begin{array}{l}\text { Kinetic-exclusion } \\
\text { analytical } \\
\text { technology }\end{array}$ & 0.21 & $0.3-20$ & [47] \\
\hline 4 & Pt nanoclusters & $\begin{array}{l}\text { Enzyme-linked } \\
\text { Immunosensor }\end{array}$ & 0.04 & $0.1-160$ & [48] \\
\hline 5 & $\begin{array}{l}\text { DA/MUC- } \\
\text { 1/fMWCNT }\end{array}$ & $\begin{array}{l}\text { Direct competitive } \\
\text { immunosensor }\end{array}$ & 0.01 & $\begin{array}{l}0.05- \\
940\end{array}$ & $\begin{array}{l}\text { Present } \\
\text { work }\end{array}$ \\
\hline
\end{tabular}

The above comparison demonstrated the advantages of developed immunosensor over the reported methods in terms of lower LOD and linear range. The lower LOD could be attributed to the direct immobilization through covalent linking that increased the accessibility of free MUC-1 to the antibody [49].

\subsection{Stability and Reproducibility}

In order to evaluate the stability, the immunosensor was stored at $4{ }^{\circ} \mathrm{C}$ after every use. The response of the immunosensor did not show any significant change over a period of two weeks, indicating the extended stability of the immunosensor. Furthermore, reproducibility of the immunosensor was also assessed. For this purpose, five immunosensors were designed independently under the optimized experimental conditions to detect the MUC-1 IC50 concentration $(7.4 \mathrm{U} / \mathrm{mL})$. The relative standard deviation (RSD) of the peak current difference was about $1.52 \%$, indicating good reproducibility of the proposed immunosensor (Fig. 8.). 

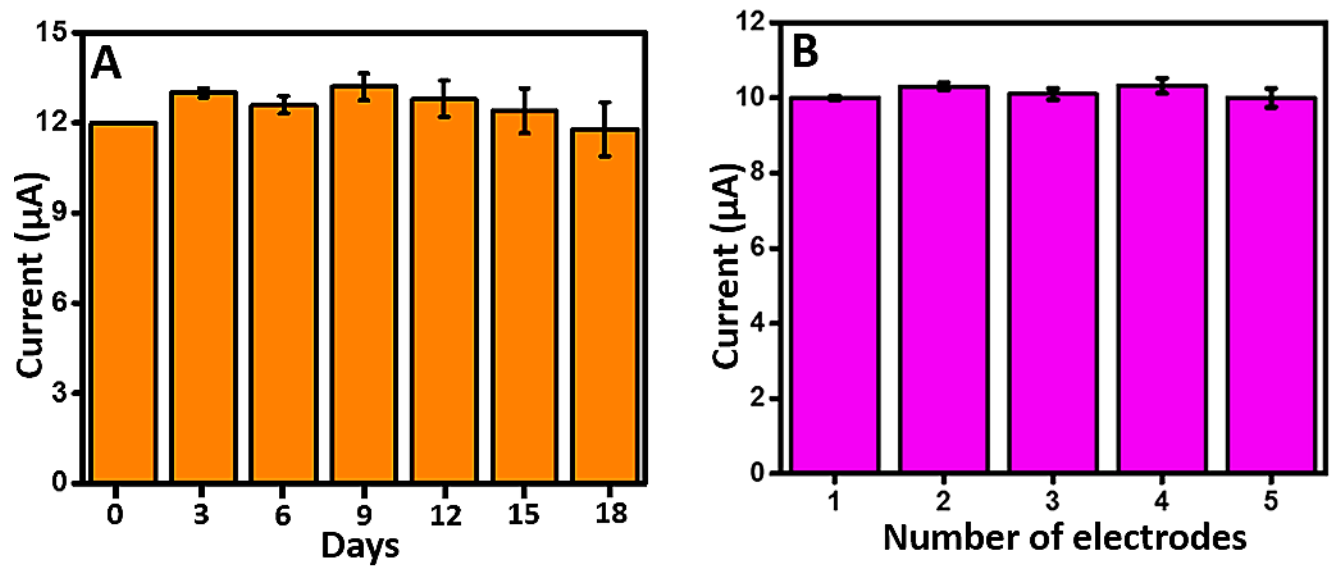

Fig. 8. (A) Stability and (B) Reproducibility of the proposed electrochemical immunosensor for the detection of $10 \mathrm{nM}$ MUC1.

\subsection{Recovery and spiked sample analysis}

In order to verify the clinical applicability of our proposed immunosensor for MUC-1 detection, human serum samples (taken from Shaukat Khanum Memorial Cancer Hospital \& Research Center, Lahore Pakistan) were spiked with three different concentrations of MUC-1 (0.1, 14.8 and $473.6 \mathrm{fU} / \mathrm{mL})$. Antibody immobilized gelatin-PGE modified electrodes were incubated with above mentioned concentrations at optimized experimental conditions with same protocol as described for standard MUC-1 analysis. Assays were performed in triplicate. Good recoveries (93.5-95\%) were obtained with R.S.D \% in the range of (4.6-6). The percentage recoveries are summarised in table 2 . These results proved the clinical applicability of the immunosensor for complex biological systems.

Table 2. Recovery percentages obtained for real sample analysis against various concentrations of MUC-1 using proposed immunosensor.

\begin{tabular}{|c|c|c|c|c|c|c|}
\hline No. & $\begin{array}{l}\text { MUC-1 added } \\
(\mathrm{U} / \mathrm{mL})\end{array}$ & $\begin{array}{l}\text { MUC-1 } \\
(\mathrm{U} / \mathrm{mL})\end{array}$ & found & R.S.D \% & R.E \% & $\mathbf{R} \%$ \\
\hline 1 & 0.1 & 0.06 & & 6 & 6.5 & 93.5 \\
\hline 2 & 14.8 & 12.9 & & 4.6 & 5 & 95 \\
\hline 3 & 473.6 & 452 & & 5 & 5.5 & 94.5 \\
\hline
\end{tabular}

R.S. $\mathrm{D}=$ Relative standard deviation, $\mathrm{R} . \mathrm{E}=$ Relative Error, $\mathrm{R}=$ Recovery

\subsection{Specificity of the Immunosensor}

477 Selectivity and specificity are important parameters to validate the practical applicability of the immunosensor. Therefore, by performing control experiment with non-specific binding proteins such as BSA, FBS and NS1, the specificity of designed immunosensor was evaluated. Fig. 9 illustrates the percentage (\%) binding response of the antibody immobilized 
as structural analogue (MUC-2) proteins. It is evident from Fig. 9 that the percentage binding response values for nonspecific proteins were considerably lower than MUC-1. However, MUC-2 showed higher response in comparison to non-specific binding proteins but much lesser than MUC-1. These results proved that the effect of non-specific proteins was insignificant on MUC-1 detection and the proposed immunosensor had sufficient specificity towards MUC-1 protein.

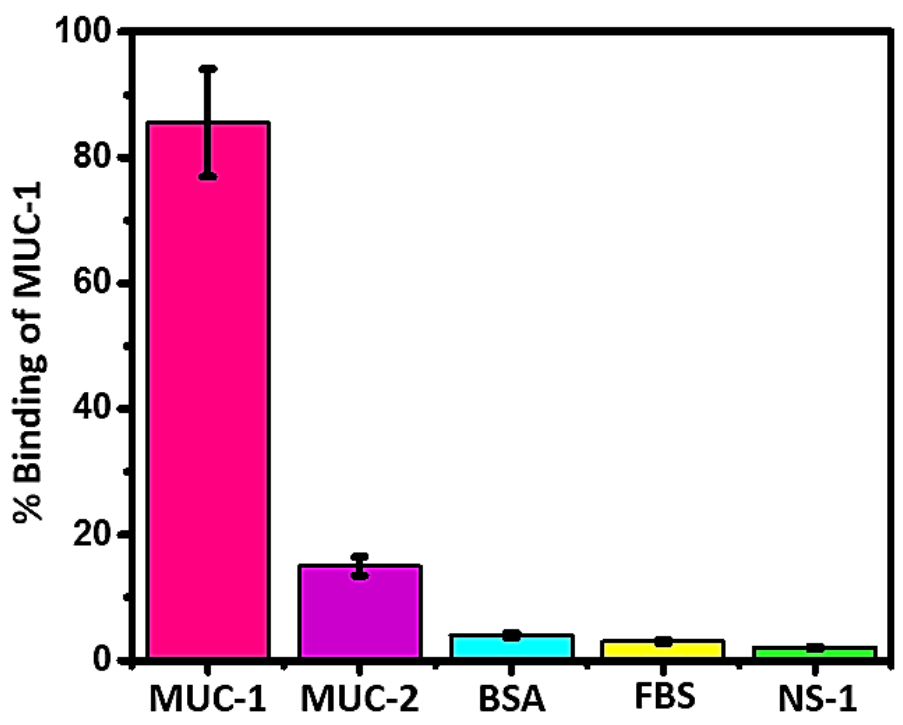

Fig. 9. Specificity of the proposed immunosensor for MUC-1 analysis.

\section{Conclusion}

In this study, a new, simple and inexpensive strategy for the detection of MUC-1 has been developed. Modification of fMWCNTs with Ag and DA provided a highly sensitive nanoprobe, which offered distinct advantages over the already reported electro-active labels in literature. On the other hand, modification of the PGE with GE facilitated to overcome the problem of biological damages and toxicity imposed by non-biological transducing materials. Both the above mentioned modifications provided an ideal and conductive platform using amino-carboxy-surface chemistry of gelatin and fMWCNTs. Compared to other reported electrochemical immunosensors for the detection of MUC-1, the proposed immunosensor functioned well over a wide linear range between $0.05-940 \mathrm{U} / \mathrm{mL}$, anda low LOD of 0.01 $\mathrm{U} / \mathrm{mL}$. Moreover, the designed immunosensor offers significant potential for widespread applications in the field of clinical diagnostics and can easily be extended to the development of other types of bio-receptor surfaces based on aptamers/antibodies for the detection of other analytes. This could not only be useful for rapid detection but also for the monitoring of the progression of disease process, which is a far bigger challenge than detection. 
506 This work was the part of project supported by HEC (Higher Education Commission), 507 Pakistan and PERIDOT, France; No. 2-3/HEC/R\&D/PERIDOT/2016. Authors acknowledge 508 the funding for this research provided by Higher Education Commission, Pakistan (5411509 FedralNRPU-R\&D-HEC-2016).

\section{Conflict of interest}

511 Authors declare no conflict of interest.

\section{References}

513 [1] S. Yang, M. You, F. Zhang, Q. Wang, P. He, A sensitive electrochemical aptasensing platform 514 based on exonuclease recycling amplification and host-guest recognition for detection of breast cancer biomarker HER2, Sensors and Actuators B: Chemical, 258(2018) 796-802.

[2] A.B. Chinen, C.M. Guan, J.R. Ferrer, S.N. Barnaby, T.J. Merkel, C.A. Mirkin, Nanoparticle probes for the detection of cancer biomarkers, cells, and tissues by fluorescence, Chemical reviews, 115(2015) 10530-74.

[3] J. Zhang, Y. Liu, X. Wang, Y. Chen, G. Li, Electrochemical assay of $\alpha$-glucosidase activity and the inhibitor screening in cell medium, Biosensors and Bioelectronics, 74(2015) 666-72.

[4] S.K. Arya, P. Zhurauski, P. Jolly, M.R. Batistuti, M. Mulato, P. Estrela, Capacitive aptasensor based on interdigitated electrode for breast cancer detection in undiluted human serum, Biosensors and Bioelectronics, 102(2018) 106-12.

[5] Y. Wan, W. Deng, Y. Su, X. Zhu, C. Peng, H. Hu, et al., Carbon nanotube-based ultrasensitive multiplexing electrochemical immunosensor for cancer biomarkers, Biosensors and Bioelectronics, 30(2011) 93-9.

[6] V. Mani, B.V. Chikkaveeraiah, V. Patel, J.S. Gutkind, J.F. Rusling, Ultrasensitive immunosensor for cancer biomarker proteins using gold nanoparticle film electrodes and multienzyme-particle amplification, ACS Nano, 3(2009) 585-94.

[7] C. Baj-Rossi, G.D. Micheli, S. Carrara, Electrochemical detection of anti-breast-cancer agents in human serum by cytochrome P450-coated carbon nanotubes, Sensors, 12(2012) 6520-37.

[8] E. Darrigues, V. Dantuluri, Z.A. Nima, K.B. Vang-Dings, R.J. Griffin, A.R. Biris, et al., Raman spectroscopy using plasmonic and carbon-based nanoparticles for cancer detection, diagnosis, and treatment guidance. Part 2: Treatment, Drug metabolism reviews, 49(2017) 253-83.

[9] J. Xue, T. Wu, Y. Dai, Y. Xia, Electrospinning and electrospun nanofibers: Methods, materials, and applications, Chemical reviews, 119(2019) 5298-415.

[10] L. Singh, H.G. Kruger, G.E. Maguire, T. Govender, R. Parboosing, The role of nanotechnology in the treatment of viral infections, Therapeutic advances in infectious disease, 4(2017) 105-31.

[11] F. Karimi, S. Alizadeh, H. Alizadeh, Immunogenicity of multi-walled carbon nanotubes functionalized with recombinant protective antigen domain 4 toward development of a nanovaccine against anthrax, Journal of Drug Delivery Science and Technology, 47(2018) 322-9.

[12] N. Xia, L. Zhang, Q. Feng, D. Deng, X. Sun, L. Liu, Amplified voltammetric detection of tyrosinase and its activity with dopamine-gold nanoparticles as redox probes, (2013).

[13] R. Zhang, Z. Fan, Nitrogen-doped carbon quantum dots as a "turn off-on" fluorescence sensor based on the redox reaction mechanism for the sensitive detection of dopamine and alpha lipoic acid, Journal of Photochemistry and Photobiology A: Chemistry, 392(2020) 112438. 
[14] X. Ji, G. Palui, T. Avellini, H.B. Na, C. Yi, K.L. Knappenberger Jr, et al., On the pH-dependent 548 quenching of quantum dot photoluminescence by redox active dopamine, Journal of the American 549 Chemical Society, 134(2012) 6006-17.

550 [15] F. Chen, Q. Wu, D. Song, X. Wang, P. Ma, Y. Sun, Fe304@ PDA immune probe-based signal and Surfaces B: Biointerfaces, 177(2019) 105-11.

[16] L. Jothi, S. Neogi, S.k. Jaganathan, G. Nageswaran, Simultaneous determination of ascorbic acid, dopamine and uric acid by a novel electrochemical sensor based on N2/Ar RF plasma assisted graphene nanosheets/graphene nanoribbons, Biosensors and Bioelectronics, 105(2018) 236-42.

[17] S.N. Topkaya, Gelatin methacrylate (GeIMA) mediated electrochemical DNA biosensor for DNA hybridization, Biosensors and Bioelectronics, 64(2015) 456-61.

[18] A.P. Periasamy, Y.-J. Chang, S.-M. Chen, Amperometric glucose sensor based on glucose oxidase immobilized on gelatin-multiwalled carbon nanotube modified glassy carbon electrode, Bioelectrochemistry, 80(2011) 114-20.

[19] F. Mollarasouli, S. Kurbanoglu, S.A. Ozkan, The role of electrochemical immunosensors in clinical analysis, Biosensors, 9(2019) 86.

[20] M. Hasanzadeh, S. Rahimi, E. Solhi, A. Mokhtarzadeh, N. Shadjou, J. Soleymani, et al., Probing the antigen-antibody interaction towards ultrasensitive recognition of cancer biomarker in adenocarcinoma cell lysates using layer-by-layer assembled silver nano-cubics with porous structure on cysteamine caped GQDs, Microchemical Journal, 143(2018) 379-92.

[21] L. Farzin, M. Shamsipur, Recent advances in design of electrochemical affinity biosensors for low level detection of cancer protein biomarkers using nanomaterial-assisted signal enhancement strategies, Journal of Pharmaceutical and Biomedical Analysis, 147(2018) 185-210.

[22] S. Centi, G. Messina, S. Tombelli, I. Palchetti, M. Mascini, Different approaches for the detection of thrombin by an electrochemical aptamer-based assay coupled to magnetic beads, Biosensors and Bioelectronics, 23(2008) 1602-9.

[23] A. Hayat, L. Barthelmebs, A. Sassolas, J.-L. Marty, An electrochemical immunosensor based on covalent immobilization of okadaic acid onto screen printed carbon electrode via diazotizationcoupling reaction, Talanta, 85(2011) 513-8.

[24] A.K. Trilling, J. Beekwilder, H. Zuilhof, Antibody orientation on biosensor surfaces: a minireview, Analyst, 138(2013) 1619-27.

[25] H.-J. Um, M. Kim, S.-H. Lee, J. Min, H. Kim, Y.-W. Choi, et al., Electrochemically oriented immobilization of antibody on poly-(2-cyano-ethylpyrrole)-coated gold electrode using a cyclic voltammetry, Talanta, 84(2011) 330-4.

[26] A.K. Trilling, M.M. Harmsen, V.J.B. Ruigrok, H. Zuilhof, J. Beekwilder, The effect of uniform capture molecule orientation on biosensor sensitivity: Dependence on analyte properties, Biosensors and Bioelectronics, 40(2013) 219-26.

[27] L. Qiao, B. Lv, X. Feng, C. Li, A new application of aptamer: One-step purification and immobilization of enzyme from cell lysates for biocatalysis, Journal of biotechnology, 203(2015).

[28] T. Kavitha, I.-K. Kang, S.-Y. Park, Poly (acrylic acid)-grafted graphene oxide as an intracellular protein carrier, Langmuir, 30(2013) 402-9.

[29] Y. Liu, Y. Fang, J. Qian, Z. Liu, B. Yang, X. Wang, Bio-inspired polydopamine functionalization of carbon fiber for improving the interfacial adhesion of polypropylene composites, RSC Advances, 5(2015) 107652-61.

[30] L. Piao, Q. Liu, Y. Li, C. Wang, Adsorption of I-Phenylalanine on Single-Walled Carbon Nanotubes, The Journal of Physical Chemistry C, 112(2008) 2857-63.

[31] E. Mwafy, Multi walled carbon nanotube decorated cadmium oxide nanoparticles via pulsed laser ablation in liquid media, Optics \& Laser Technology, 111(2019) 249-54.

[32] W. Wei, D.F. Li, X.H. Pan, S.Q. Liu, Electrochemiluminescent detection of Mucin 1 protein and MCF-7 cancer cells based on the resonance energy transfer, Analyst, 137(2012) 2101-6. 
[33] T. Maxwell, T. Banu, E. Price, J. Tharkur, M.G.N. Campos, A. Gesquiere, et al., Non-cytotoxic 598 quantum dot-chitosan nanogel biosensing probe for potential cancer targeting agent, $599 \quad$ Nanomaterials, 5(2015) 2359-79.

600 [34] P. Nie, C. Min, H.-J. Song, X. Chen, Z. Zhang, K. Zhao, Preparation and Tribological Properties of 601 Polyimide/Carboxyl-Functionalized Multi-walled Carbon Nanotube Nanocomposite Films Under Seawater Lubrication, Tribology Letters, 58(2015).

[35] V.N. Boya, R. Lovett, S. Setua, V. Gandhi, P.K.B. Nagesh, S. Khan, et al., Probing mucin interaction behavior of magnetic nanoparticles, Journal of Colloid and Interface Science, 488(2017) 258-68.

[36] V.K. Thakur, J. Yan, M.-F. Lin, C. Zhi, D. Golberg, Y. Bando, et al., Novel polymer nanocomposites from bioinspired green aqueous functionalization of BNNTs, Polym Chem, 3(2012) 962-9.

[37] A.M. Mohammed, I.K. Al-Khateeb, A.J. Haider, R.A. Rahim, U. Hashim, Preparation of DNA biosensor application from fuel oil waste by functionalization and characterization of MWCNT, Sensing and Bio-Sensing Research, 16(2017) 1-5.

[38] S. Co, Functionalized multi-walled carbon nanotubes for enhanced photocurrent in dyesensitized solar cells, Journal of Nanostructure in Chemistry, 19(2013).

[39] L. Radev, M. Fernandes, I. Salvado, D. Kovacheva, Organic/Inorganic bioactive materials Part III: in vitro bioactivity of gelatin/silicocarnotite hybrids, Central European Journal of Chemistry, $7(2009)$ 721-30.

[40] M.H. Nawaz, A. Hayat, G. Catanante, U. Latif, J.L. Marty, Development of a portable and disposable NS1 based electrochemical immunosensor for early diagnosis of dengue virus, Analytica Chimica Acta, 1026(2018) 1-7.

[41] C. Ye, M.Q. Wang, Z.F. Gao, Y. Zhang, J.L. Lei, H.Q. Luo, et al., Ligating Dopamine as Signal Trigger onto the Substrate via Metal-Catalyst-Free Click Chemistry for "Signal-On" Photoelectrochemical Sensing of Ultralow MicroRNA Levels, Analytical Chemistry, 88(2016) 11444-9. [42] Y. Lin, Q. Zhou, D. Tang, Dopamine-Loaded Liposomes for in-Situ Amplified Photoelectrochemical Immunoassay of AFB1 to Enhance Photocurrent of Mn2+-Doped Zn3(OH)2V2O7 Nanobelts, Analytical Chemistry, 89(2017) 11803-10.

[43] M. Hasanzadeh, M. Feyziazar, E. Solhi, A. Mokhtarzadeh, J. Soleymani, N. Shadjou, et al., Ultrasensitive immunoassay of breast cancer type 1 susceptibility protein (BRCA1) using poly (dopamine-beta cyclodextrine-Cetyl trimethylammonium bromide) doped with silver nanoparticles: A new platform in early stage diagnosis of breast cancer and efficient management, Microchemical Journal, 145(2019) 778-83.

[44] Y. Fu, K. Zou, M. Liu, X. Zhang, C. Du, J. Chen, Highly Selective and Sensitive Photoelectrochemical Sensing Platform for VEGF165 Assay Based on the Switching of Photocurrent Polarity of CdS QDs by Porous Cu2O-CuO Flower, Analytical Chemistry, 92(2020) 1189-96.

[45] C.-C. Chang, N.-F. Chiu, D.S. Lin, Y. Chu-Su, Y.-H. Liang, C.-W. Lin, High-sensitivity detection of carbohydrate antigen 15-3 using a gold/zinc oxide thin film surface plasmon resonance-based biosensor, Analytical chemistry, 82(2010) 1207-12.

[46] S. Rauf, G.K. Mishra, J. Azhar, R.K. Mishra, K.Y. Goud, M.A.H. Nawaz, et al., Carboxylic group riched graphene oxide based disposable electrochemical immunosensor for cancer biomarker detection, Analytical Biochemistry, 545(2018) 13-9.

[47] I.A. Darwish, T.A. Wani, N.Y. Khalil, D.A. Blake, Novel automated flow-based immunosensor for real-time measurement of the breast cancer biomarker CA15-3 in serum, Talanta, 97(2012) 499-504. [48] W. Li, R. Yuan, Y. Chai, S. Chen, Reagentless amperometric cancer antigen 15-3 immunosensor based on enzyme-mediated direct electrochemistry, Biosensors and Bioelectronics, 25(2010) 254852.

[49] A.-E. Radi, X. Muñoz-Berbel, V. Lates, J.-L. Marty, Label-free impedimetric immunosensor for sensitive detection of ochratoxin A, Biosensors and Bioelectronics, 24(2009) 1888-92. 
Prof. Jean Louis Marty has a strong background in the field of biotechnology and an extensive experience in the domain of optical and electrochemical biosensors, protein stabilization methodologies and bio-receptors immobilization techniques. His specialisation also includes, but is not restricted to implementation of biosensors for the detection of pesticides, marine toxines and mycotoxines. He is the founder of two companies in the field of biotechnology and biosensors. He has been awarded several national and international projects in the field of biosensors, mainly funded by European Agency projects Frame V, VI, VII, NATO, INTERREG, National call. Additionally, he has supervised 27 PhDs with 22 foreign students.

Dr. Akhtar Hayat is currently working as an Assistant Professor at IRCBM, COMSATS Lahore, Pakistan. He received MS/Ph.D. Degree in biosensors from Universite de perpignan, France and post doc from Clarkson University, USA in nano-biosensors. He is the founder of sensors/biosensors research group at IRCBM, COMSATS, Lahore, and acting as a head of this group. Dr Akhtar Hayat has licensed a patent technology with Eco global foods and working on many other applied project with commercial impact. Dr Akhtar Hayat is playing a key role towards the development of this group based on his international collaborations and national research funding. He is also very progressive for working in collaboration with research groups from National Institution in Pakistan. Dr Akhtar Hayat has published various research articles in the prominent and prestigious international journals including Advanced Health Care Materials, NanoScale, Analytical Chemistry and Biosensors \& bioelectronics. He is also author of many international book chapters, as well as PI for many research grants.

Prof. Ihtesham ur Rehman is Professor of Bioengineering at Lancaster University. His expertise covers a wide range of research topics relating to biomaterials and spectroscopy, including chemical structural evaluations of cells (cancer cells) and tissues using FTIR and Raman spectroscopic techniques, the use of vibrational spectroscopy to study, microbial interactions with blood, tissues or surfaces and creation of bioactive functionalised materials with improved chemical, mechanical and biological properties.

Dr. Mian Hasnain Nawaz earned his $\mathrm{PhD}$ in Materials Science and Engineering from East China University of Science and Technology, Shanghai (2013). During his doctoral dissertation he mainly focused on polymer chemistry and porphyrin-fullerene nano-composites. In details he has worked on; Synthesis and characterization of metal complexes, Synthesis and 
functionalization of different Porphyrin, Graphene and Fullerene derivatives, Decoration of porphyrin and fullerene derivatives with different types of polymers including $\mathrm{pH}, \mathrm{UV}$ and thermosensitive polymers via RAFT and Click-chemistry approaches, Synthesis of metallic nanoparticles for their electrochemical and catalytic studies, Fabrication and modification of different types of electrodes via Electrospinning and sputtering for biosensors and bio-fuel cell applications, Fabrication of modified electrodes and development of different aptasensors and immunosensors.

Sidra Rashid was born in Mirpur Azad Kashmir (AJK), Pakistan and received Bachelor's degree in Chemistry from Mirpur University of Science and Technology (MUST), AJK in 2014. She continued to study Chemistry and received Master's degree from University of Kotli (UOK) in 2017. After that, she started working as a research assistant in Sensor \& Biosensors Lab at Interdisciplinary Research Center of Biomedical Materials, COMSATS University Islamabad, Lahore. Her interests are mainly directed to the use of nanomaterials that can be incorporated for biosensing applications. 


\section{CONFLICT OF INTEREST}

Authors do not declare any kind of conflict of interest. 
$$
\text { Credit Author Statement }
$$

1. Sidra Rashid: Investigation, Writing - Original Draft, Visualization.

2. Mian Hasnain Nawaz: Writing - Review \& Editing.

3. Ihtesham ur Rehman: Resources.

4. Akhtar Hayat: Conceptualization, Methodology, Supervision.

5. Jean Loius Marty: Validation. 


\section{Click here to access/download Supplementary Material Supplementary data.docx}

